\title{
Vibration Characteristics of Carbon Fiber Reinforced Polymer Composites under Varying Fiber Orientation Composition
}

\author{
Nazirul Muhaimin Hamzi, Mohammad Rasidi Rasani, Mohd Faizal Mat Tahir, Mohammad \\ Hamdan Sanusi
}

\begin{abstract}
Many engineering applications today are increasingly made of laminated composite plates. The properties of laminated composite plates can change as the laminate and fiber composition change, enabling the engineering structure and components to be customized according to the desired static or dynamic properties. Therefore, it is of interest to investigate variation in dynamic properties of composites under different fiber orientation composition to forecast their vibration response. In this study, the natural frequency and mode shape of carbon fiber-reinforced polymer composite plates were obtained numerically under varying composition of the $0^{\circ}, \pm 45^{\circ}$ and $90^{\circ}$ fiber orientations. Sixteen different cases were simulated using finite element method, showing changes in the natural frequency and mode shape of carbon fiber-reinforced polymer composite plates with changes in the composition of the fiber orientation. The first five values of natural frequency and mode shape of the composite laminate were reported and analyzed using a surface regression method. In addition, the effect of the stacking sequence on the natural frequency of the composite plate having the same orientation composition was also analyzed. Comparison with previous studies showed good agreement of the present numerical modeling. Numerical results indicate potential to develop relationships to estimate modal properties based on composition of fiber orientation.
\end{abstract}

Keywords : Carbon fiber-reinforced polymer (CFRP), Natural frequency, Mode shapes, Fiber orientation, Stacking composition.

\section{INTRODUCTION}

Composite lamina is a combination of fiber and matrix material that produce new properties that cannot be achieved with fiber or matrix alone [1]. Conventional fibers typically

Revised Manuscript Received on December 30, 2019.

* Correspondence Author

Nazirul Muhaimin Hamzi, Faculty of Engineering \& Built Environment, Universiti Kebangsaan Malaysia, 43600 Bangi, Selangor, Malaysia.

Mohammad Rasidi Rasani*, Center for Integrated Design for Advanced Mechanical Systems, Faculty of Engineering \& Built Environment, Universiti Kebangsaan Malaysia, 43600 Bangi, Selangor, Malaysia.

Mohd Faizal Mat Tahir, Center for Integrated Design for Advanced Mechanical Systems, Faculty of Engineering \& Built Environment, Universiti Kebangsaan Malaysia, 43600 Bangi, Selangor, Malaysia.

Mohammad Hamdan Sanusi, CTRM Aero Composites SDN BHD, 75350 Batu Berendam, Melaka, Malaysia.

(c) The Authors. Published by Blue Eyes Intelligence Engineering and Sciences Publication (BEIESP). This is an open access article under the CC BY-NC-ND license (http://creativecommons.org/licenses/by-nc-nd/4.0/) used in composite laminates include carbon and glass fibers, but recently natural fibers such as kenaf [2] and ramie [3] have also been used due to their favorable cost, weight, sustainability and environmental impact. Composites properties depend on the direction of the fiber orientation. The use of composites in aircraft manufacturing industry is increasing every year. According to Bachmann et al. mechanical properties of composite such as elastic modulus, specific gravity, and ultimate tensile strength are better than steel and aluminium [4]. Composites also have good fatigue behavior. It is also reported that over $50 \%$ of the materials used in the aircraft manufacturing are from composite material [4]. For example, in the Airbus 350, components are made of different compositions of materials such as composite, aluminium-lithium, titanium, steel and other materials - which make up approximately 53\%, 19\%, 14\%, $6 \%$, and $8 \%$ respectively, of the total material used. Apart for aerospace or automotive structures, composites have also been found in other applications such as those proposed for energy harvesting membranes [5], sensors using macro-fiber composites [6] and noise insulation [7]. Although composite offer favorable mechanical properties than other materials, they are still exposed to the resonance. Resonance occur when the frequency of applied forced is same or near to the natural frequency of the material. Vibration characteristics of composite like its natural frequencies and mode shape, always change with the fiber orientation in the lamina. Therefore, the composite material can be designed or customized according to the desired properties by changing the fiber orientation by applying different orientation angle, stacking sequence, volume fraction and different compositions of fiber orientation. From the literature, there are previous studies undertaken on the effect of changing the fiber orientation on natural frequencies and mode shapes. Sadr et al. studied the free vibration analysis of rotating laminated composite panels using finite strip method with modified shape functions [8]. Ahmed et al. investigated the analysis of static and dynamic properties of laminated composite plate using finite element method [9]. The study was focused on effect of fiber orientation and number of layers on the natural frequency. Srinivasa et al. studied the free vibration of isotropic and laminated skew plate using experimental and finite element method [10]. The study was focused on effect change of skew angle, angle of fiber orientation and stacking sequence on the natural frequencies and mode shape. 


\section{Vibration Characteristics of Carbon Fiber Reinforced Polymer Composites under Varying Fiber Orientation Composition}

The simulation was run using MSC/NASTRAN since the study used finite element method for their vibration analysis.

Balci et al. studied the effect of the ply angles and boundary condition on the natural frequencies of laminated beam composite using finite element method and the problem was solved using MATLAB program [11]. Huifen et al. studied the effect of fiber orientation angle on the vibration characteristic of the laminated composite plate [12]. The natural frequency will increase when the fiber orientation angle increase - leading to various vibration characteristics of the laminated plates and increasing design flexibility of structures.

Pingulkar and Suresha studied effect of different stacking sequences of cantilevered hybrid laminated composite plate on the natural frequencies using finite element method in ANSYS software [13]. The study used a quasi-isotropic glass/carbon layup and had focused on the effect of change in fiber volume fraction, matrix material and stacking sequences on natural frequency of laminate composite plate. Mahdi et al. investigated the effect of fiber orientation on the natural frequencies of the laminated graphite/epoxy composite beam using finite element method with different boundary conditions [14]. The study was focused on the natural frequency of symmetry and non-symmetry laminated composite beam at specific +/- fiber angle combinations. Norman et al. studied the natural frequency of carbon fiber reinforced polymer laminated beam composite at various thickness of plate and boundary conditions [15]. Effect of various laminated scheme for 3 different orientations (cross-plies, angle-plies and unidirectional plies) on their natural frequencies was performed using ANSYS software. Khare et al. investigated effect of different fiber orientation, radius ratio, and thickness ratio on the natural frequency and mode shape of circular laminated composites plates [16]. The plates were modelled with free, clamped and simply supported boundary condition. Kadioglu et al. studied the effect of various of fiber orientation (at specific +/- angle combinations) on natural frequency of glass fiber reinforced cantilevered laminated composite plate [17]. Muhammet et al. analyzed the free vibration characteristics of symmetric laminated cantilevered composite plate for four different fiber orientations [18].

From the literature review, although a number of studies had looked at effect of fiber orientation on composite plate vibration characteristics, most had focused on particular layups or orientation angles, rather than the effect of overall $\%$ fiber orientation composition of the composite laminate. Therefore, the aim in this study is to analyze the effect of fiber orientation composition on the natural frequencies and mode shape of carbon fiber reinforced polymer (CFRP) composite plates. As most engineering application involves $0^{\circ} / 90^{\circ}$ plies aligned in the loading direction (to take up the applied tensile/compressive loading) and $\pm 45^{\circ}$ plies good for taking up shear loads, we focused our composition on the $\%$ content of $\left[0 \%+\underline{4} \% / 90^{\circ}\right]$ fiber orientations in the laminate. To that end, we limit our attention to symmetric laminates and several boundary conditions of the plate edges. We also included in our study, the effect of different stacking sequences on the natural frequency of the composite laminate. Overall, the study had focused on 16 cases, consisting of a combination of layups of the form $\left[0^{\circ} \mathrm{n} / \pm 45^{\circ}{ }_{n} / 90^{\circ}{ }_{n}\right]_{s}$ (where $n$ denotes number of plies for each fiber orientation and s denotes symmetrical stacking).

\section{METHODOLOGY}

\section{A. Computational model and boundary conditions}

The laminated plate composite modelled was a $1 \mathrm{~m}$ x $1 \mathrm{~m} x$ $2 \mathrm{~mm}$ (thick) square, consisting of 10 numbers of $0.2 \mathrm{~mm}$ layers as shown in Fig. 1. Fig. 1 shows the schematic diagram of the laminated composite plate consisting 10 number of layers, where every ply or layer fiber orientation $\left(\theta^{\circ}\right)$ are either $0^{\circ}, \pm 45^{\circ}$ or $90^{\circ}$. Fig. 2 shows orientation composition of the laminated composite plate, highlighting that (as all plies are of same thickness) each ply contribute to $10 \%$ composition of fiber orientation $\theta^{\circ}$ of that ply.

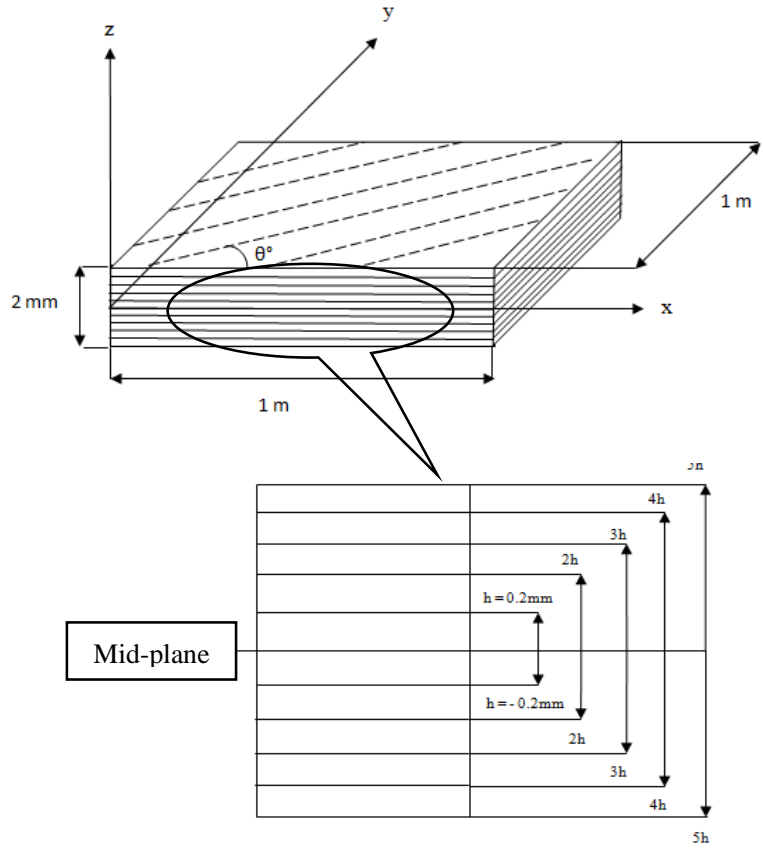

Fig. 1. Laminated Composite Plate

\begin{tabular}{cc}
\hline Layer 1 \\
\hline Layer 2 \\
\hline Layer 3 \\
\hline Layer 4 \\
\hline Layer 5 \\
\hline Layer 6 \\
\hline Layer 7 \\
\hline Layer 8 \\
\hline Layer 9 \\
\hline Layer 10
\end{tabular}

$$
\begin{gathered}
10 \% \text { of composition } \\
\text { orientation } \theta^{\circ} \\
10 \% \text { of composition } \\
\text { orientation } \theta^{\circ} \\
10 \% \text { of composition } \\
\text { orientation } \theta^{\circ} \\
10 \% \text { of composition } \\
\text { orientation } \theta^{\circ} \\
10 \% \text { of composition } \\
\text { orientation } \theta^{\circ} \\
10 \% \text { of composition } \\
\text { orientation } \theta^{\circ} \\
10 \% \text { of composition } \\
\text { orientation } \theta^{\circ} \\
10 \% \text { of composition } \\
\text { orientation } \theta^{\circ} \\
10 \% \text { of composition } \\
\text { orientation } \theta^{\circ} \\
10 \% \text { of composition } \\
\text { orientation } \theta^{\circ}
\end{gathered}
$$

Fig. 2. Composition of fiber orientation $\theta$

The modal analysis of the laminated composite plate was performed using a finite element method (FEM) undertaken in MSC PATRAN/NASTRAN.

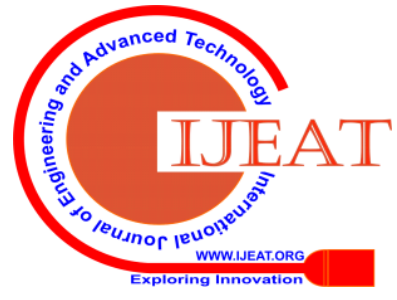


The material properties of CFRP used were based from Lee et al. [19] and are shown in Table I. The laminated plate composite is modelled using two-dimensional isoparametric elements. Hence, four node quadrilateral elements were applied to xy-surface of the laminated composite plate as shown in Fig. 3. As a free vibration analysis of plate composite was undertaken, no external force was applied to the plate.

In total, 6 types of boundary condition combinations were applied at all 4 edges of the laminated composite. The 6 boundary conditions were: simple-simple-simple-simple (SSSS), clamped-simple-simple-simple (CSSS), clampedfree-clamped-free (CFCF), free-simple-free-simple (FSFS), clamped-clamped-clamped-clamped (CCCC) and simplesimple-free-simple (SSFS). For each of the 6 boundary conditions, 16 different cases or layups were applied on the composite plate - the layups are summarized in Table III. For each case or layup, the first 5 natural frequencies and mode shapes were solved and recorded. This modal simulation for all 16 cases or layup is repeated for each of the 6 boundary conditions considered in the present study.

\section{Table-I: Material Properties of CFRP}

\begin{tabular}{|c|c|c|c|}
\hline $\begin{array}{c}\text { Material } \\
\text { Properties }\end{array}$ & Symbol & Units & CFRP \\
\hline $\begin{array}{c}\text { Elastic } \\
\text { modulus 11 }\end{array}$ & $\mathrm{E}_{11}$ & $\mathrm{~Pa}$ & $1.81 \times 10^{+11}$ \\
\hline $\begin{array}{c}\text { Elastic } \\
\text { modulus 22 }\end{array}$ & $\mathrm{E}_{22}$ & $\mathrm{~Pa}$ & $1.03 \times 10^{+10}$ \\
\hline $\begin{array}{c}\text { Poisson's } \\
\text { ratio }\end{array}$ & $\mathrm{V}_{12}$ & - & 0.28 \\
\hline $\begin{array}{c}\text { Shear } \\
\text { modulus 12 }\end{array}$ & $\mathrm{G}_{12}$ & $\mathrm{~Pa}$ & $7.12 \times 10^{+09}$ \\
\hline $\begin{array}{c}\text { Shear } \\
\text { modulus 13 }\end{array}$ & $\mathrm{G}_{23}$ & $\mathrm{~Pa}$ & $2.50 \times 10^{+09}$ \\
\hline $\begin{array}{c}\text { Shear } \\
\text { modulus 23 }\end{array}$ & $\mathrm{G}_{13}$ & $\mathrm{~Pa}$ & $7.12 \times 10^{+09}$ \\
\hline Density & $\mathrm{P}$ & $\mathrm{kg} / \mathrm{m}^{3}$ & 1600 \\
\hline
\end{tabular}

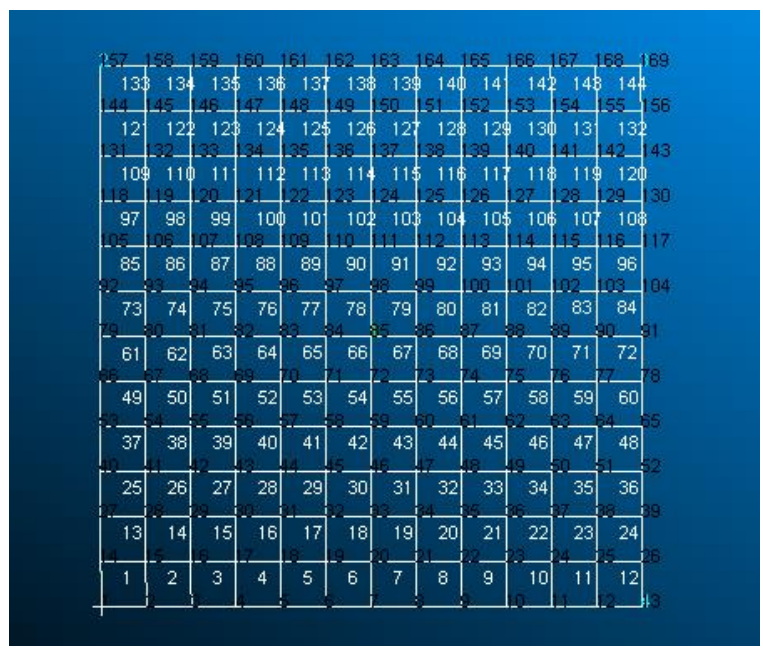

Fig. 3. Mesh size of composite plate

\section{B. Validation}

A mesh-independent study was performed in order to find the optimum number of elements for the present modal investigation. Fig. 4 shows that the natural frequency obtained from the finite element simulation of the laminated plate is stabilized when the number of mesh reached 144 elements and is practically unchanged when the number of mesh was further increased.. Therefore, the baseline grid used in the present model was set to 144 elements.

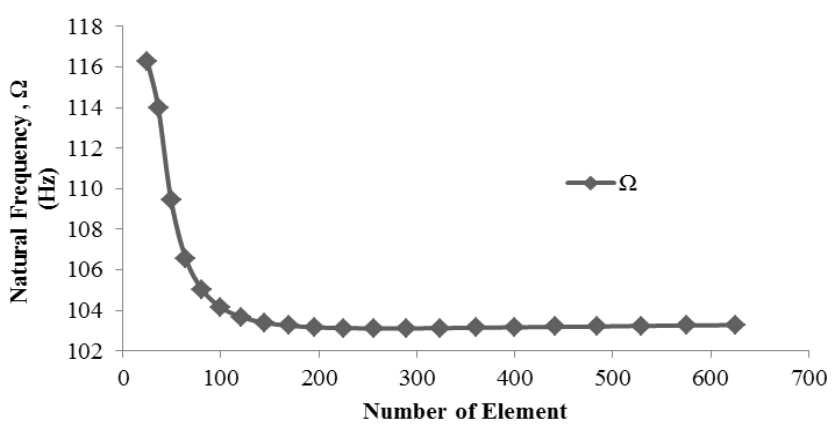

Fig. 4. Mesh-independence study

The accuracy of the procedure in this study was further verified by comparing to results from previous work as shown in Table II. Pushparaj and Suresha [13] had analyzed the free vibration of symmetric laminated plate using the finite element method (ANSYS). The material properties used to compare with previous work was the same used by Pushparaj and Suresha [13]. The results in all cases between presented work and previous study show no difference of more than $3 \%$.

Table-II: Comparison with previous study

\begin{tabular}{|c|c|c|c|c|}
\hline Lamina & Mode & $\begin{array}{c}\text { Numerical } \\
{[13](\mathrm{Hz})}\end{array}$ & $\begin{array}{c}\text { Present } \\
\text { work (Hz) }\end{array}$ & $\begin{array}{l}\text { Diff. } \\
(\%)\end{array}$ \\
\hline \multirow{5}{*}{$\begin{array}{c}{[0 \% \%} \\
\left.30 \%-30^{\circ}\right] \mathrm{s}\end{array}$} & 1 & 261.3 & 260.4 & 0.3 \\
\hline & 2 & 361.8 & 359.3 & 0.7 \\
\hline & 3 & 755.4 & 745.8 & 1.3 \\
\hline & 4 & 1591.4 & 1561.6 & 1.9 \\
\hline & 5 & 1626.2 & 1596.1 & 1.9 \\
\hline \multirow{5}{*}{$\begin{array}{c}{\left[0 \% / 45^{\circ} /\right.} \\
\left.-45^{\circ} / 90^{\circ}\right] \mathrm{s}\end{array}$} & 1 & 223.6 & 222.9 & 0.3 \\
\hline & 2 & 419.4 & 415.5 & 0.9 \\
\hline & 3 & 1004.2 & 988.8 & 1.6 \\
\hline & 4 & 1402.5 & 1383.2 & 1.4 \\
\hline & 5 & 1619.4 & 1657.4 & 2.3 \\
\hline \multirow{5}{*}{$\begin{array}{l}{\left[45^{\circ} /-45^{\circ} /\right.} \\
\left.-45^{\circ} / 45^{\circ}\right] \mathrm{s}\end{array}$} & 1 & 137.7 & 136.7 & 0.7 \\
\hline & 2 & 494.0 & 486.4 & 1.6 \\
\hline & 3 & 789.5 & 777.2 & 1.6 \\
\hline & 4 & 1304.4 & 1276.8 & 2.2 \\
\hline & 5 & 1607.6 & 1565.7 & 2.7 \\
\hline
\end{tabular}

\section{RESULTS AND DISCUSSION}

The study had focused on 16 cases or combination of fiber orientation composition for the laminated composite plate as shown in Table III (each case consisted of 10 number of layers or plies). Cases 2, 3, 4 represent a combination of fiber orientation composed of $\left[ \pm 45^{\circ}{ }_{n} / 90^{\circ}{ }_{n}\right]_{s}$ only (hence $0 \%$ of $0^{\circ}$ fiber orientation). Cases $6,10,13,15$ represent a combination of fiber orientation composed of $\left[0^{\circ}{ }_{n} / 90^{\circ}\right]_{s}$ only (hence $0 \%$ of $\pm 45^{\circ}$ fiber orientation). Cases $9,12,14$ represent the combination of fiber orientation composed of $\left[0^{\circ} / \pm 45^{\circ}\right]_{s}$ only (hence $0 \%$ of $90^{\circ}$ fiber orientation). 


\section{Vibration Characteristics of Carbon Fiber Reinforced Polymer Composites under Varying Fiber Orientation Composition}

Cases 7, 8, 11 represents the combination of fiber orientation composed of $\left[0^{\circ}{ }_{n} / \pm 45^{\circ}{ }_{n} / 90^{\circ}{ }_{n}\right]_{s}$. While cases $16,5,1$ (in addition to their fiber orientation composition) were also used to analyze the effect of changing fiber orientation from $0^{\circ}$ to $\pm 45^{\circ}$ to $90^{\circ}$. It is noted that subscripts ' $n$ ' and ' $s$ ' denotes number of plies for the particular fiber orientation and symmetric stacking respectively. In addition, all 16 cases/layups were used for each type of plate boundary conditions selected in the present study (i.e. SSSS, CSSS, CFCF, FSFS, CCCC, SSFS).

Table-III: Stacking sequence of each case

\begin{tabular}{|c|c|c|c|c|}
\hline \multirow{2}{*}{ Case } & \multicolumn{3}{|c|}{$\begin{array}{c}\text { Composition } \\
\text { orientation (\%) }\end{array}$} & \multirow{2}{*}{ Stacking sequences } \\
\cline { 2 - 4 } & $0^{\circ}$ & $\pm 45^{\circ}$ & $90^{\circ}$ & \\
\hline $\mathbf{1}$ & 0 & 0 & 100 & {$\left[90^{\circ} / 90^{\circ} / 90^{\circ} / 90^{\circ} / 90^{\circ}\right] \mathrm{s}$} \\
\hline $\mathbf{2}$ & 0 & 40 & 60 & {$\left[-45^{\circ} / 45^{\circ} / 90^{\circ} / 90^{\circ} / 90^{\circ}\right] \mathrm{s}$} \\
\hline $\mathbf{3}$ & 0 & 60 & 40 & {$\left[45^{\circ} / 45^{\circ} / 45^{\circ} / 90^{\circ} / 90^{\circ}\right] \mathrm{s}$} \\
\hline $\mathbf{4}$ & 0 & 80 & 20 & {$\left[-45^{\circ} / 45^{\circ} /-45^{\circ} / 45^{\circ} / 90^{\circ}\right] \mathrm{s}$} \\
\hline $\mathbf{5}$ & 0 & 100 & 0 & {$\left[45^{\circ} / 45^{\circ} / 45^{\circ} / 45^{\circ} / 45^{\circ}\right] \mathrm{s}$} \\
\hline $\mathbf{6}$ & 20 & 0 & 80 & {$\left[0^{\circ} / 90^{\circ} / 90^{\circ} / 90^{\circ} / 90^{\circ}\right] \mathrm{s}$} \\
\hline $\mathbf{7}$ & 20 & 40 & 40 & {$\left[0^{\circ} /-45^{\circ} / 45^{\circ} / 90^{\circ} / 90^{\circ}\right] \mathrm{s}$} \\
\hline $\mathbf{8}$ & 20 & 60 & 20 & {$\left[0^{\circ} / 45^{\circ} /-45^{\circ} / 45^{\circ} / 90^{\circ}\right] \mathrm{s}$} \\
\hline $\mathbf{9}$ & 20 & 80 & 0 & {$\left[0^{\circ} /-45^{\circ} / 45^{\circ} / 45^{\circ} / 45^{\circ}\right] \mathrm{s}$} \\
\hline $\mathbf{1 0}$ & 40 & 0 & 60 & {$\left[0^{\circ} / 0^{\circ} / 90^{\circ} / 90^{\circ} / 90^{\circ}\right] \mathrm{s}$} \\
\hline $\mathbf{1 1}$ & 40 & 40 & 20 & {$\left[0^{\circ} / 0^{\circ} / 45^{\circ} / 45^{\circ} / 90^{\circ}\right] \mathrm{s}$} \\
\hline $\mathbf{1 2}$ & 40 & 60 & 0 & {$\left[0^{\circ} / 0^{\circ} / 45^{\circ} / 45^{\circ} / 45^{\circ}\right] \mathrm{s}$} \\
\hline $\mathbf{1 3}$ & 60 & 0 & 40 & {$\left[0^{\circ} / 0^{\circ} / 0 / 90^{\circ} / 90^{\circ}\right] \mathrm{s}$} \\
\hline $\mathbf{1 4}$ & 60 & 40 & 0 & {$\left[0^{\circ} / 0^{\circ} / 0^{\circ} /-45^{\circ} / 45^{\circ}\right] \mathrm{s}$} \\
\hline $\mathbf{1 5}$ & 80 & 0 & 20 & {$\left[0^{\circ} / 0^{\circ} / 0^{\circ} / 0^{\circ} / 90^{\circ}\right] \mathrm{s}$} \\
\hline $\mathbf{1 6}$ & 100 & 0 & 0 & {$\left[0^{\circ} / 0^{\circ} / 0^{\circ} / 0^{\circ} / 0^{\circ}\right] \mathrm{s}$} \\
\hline
\end{tabular}
A. Effect of change in fiber orientation composition on
natural frequency

Table IV tabulates the results of natural frequency for all the 16 cases or layups, for all the boundary conditions considered in the present numerical experiment. This is further illustrated in Fig. 6-11 showing the surface plot of variation in natural frequency against fiber orientation composition, for the 6 respective boundary conditions simulated in the present modal analysis. The surface plot are presented with the $\mathrm{x}$-axis representing \% of fiber orientation in the $0^{\circ}$ and the $y$-axis representing the $\%$ of fiber orientation in the $90^{\circ}$. As the general layup of all the laminates are of the form $\left[0^{\circ}{ }_{n} / \pm 45^{\circ}{ }_{n} / 90^{\circ}{ }_{n}\right]_{s}$, the remaining \% represents the content of the $\pm 45^{\circ}$ fiber orientation. Along the figures, a two-dimensional surface fitting equation is proposed and included, allowing estimation of natural frequency based on the $\mathrm{x}$ - and $\mathrm{y}$-variables (i.e. \% of $0^{\circ}$ fiber orientation and $90^{\circ}$ fiber orientation contents respectively). For each boundary condition case, a $4^{\text {th }}$-order polynomial appears to give the best surface equation fit, as indicated by the correlation coefficient $\mathrm{R}^{2}$ (which measures the variance in the accuracy of the predicted natural frequency from the $\% 0^{\circ}$ and $90^{\circ}$ fiber orientation input variable, and where an $\mathrm{R}^{2}=1.0$ indicates strong correlation and accuracy). The lowest $\mathrm{R}^{2}$ of 0.92 among all the boundary conditions studied, suggests reasonable correlation and accuracy of the proposed equations to predict the natural frequency. It is remarked that $\%$ of $0^{\circ}$ fiber orientation composition $+\% 90^{\circ}$ fiber orientation composition must be less than or equal to $100 \%$ in these equations, due to obvious physical constraint that total $\%$ of fiber orientation contents in the laminate must not exceed $100 \%$.

Table-IV: Natural frequency results for each case at various boundary conditions

\begin{tabular}{|c|c|c|c|c|c|c|c|c|c|}
\hline \multirow{2}{*}{ Ü } & \multicolumn{3}{|c|}{$\begin{array}{c}\text { Composition } \\
\text { orientation (\%) }\end{array}$} & \multicolumn{6}{|c|}{ Natural frequency $(\mathrm{Hz})$} \\
\hline & $0^{\circ}$ & $\pm 45^{\circ}$ & $90^{\circ}$ & W & $\begin{array}{l}\tilde{D} \\
\tilde{u}\end{array}$ & 岂 & $\begin{array}{l}\infty \\
\text { D } \\
\text { L }\end{array}$ & ن & 崩 \\
\hline 1 & 0 & 0 & 100 & 40.8 & 42.9 & 23.7 & 32.4 & 61.1 & 38.8 \\
\hline 2 & 0 & 40 & 60 & 54.1 & 60.3 & 35.6 & 31.4 & 70.3 & 40.1 \\
\hline 3 & 0 & 60 & 40 & 57.4 & 61.7 & 37.5 & 29.6 & 74.1 & 40.4 \\
\hline 4 & 0 & 80 & 20 & 58.2 & 60.4 & 38.5 & 29.1 & 75.0 & 40.5 \\
\hline 5 & 0 & 100 & 0 & 58.1 & 60.2 & 38.5 & 29.0 & 74.9 & 40.6 \\
\hline 6 & 20 & 0 & 80 & 63.8 & 65.7 & 44.1 & 29.4 & 87.4 & 36.6 \\
\hline 7 & 20 & 40 & 40 & 49.5 & 54.1 & 47.6 & 24.8 & 66.9 & 42.9 \\
\hline 8 & 20 & 60 & 20 & 49 & 54.6 & 48.1 & 25.0 & 66.4 & 39.7 \\
\hline 9 & 20 & 80 & 0 & 49 & 54.7 & 48.1 & 25.0 & 66.3 & 39.2 \\
\hline 10 & 40 & 0 & 60 & 46.6 & 49.9 & 53.8 & 21.4 & 64.7 & 44.3 \\
\hline 11 & 40 & 40 & 20 & 44.9 & 52.8 & 49.6 & 23.6 & 64.7 & 31.1 \\
\hline 12 & 40 & 60 & 0 & 44.9 & 52.9 & 48.9 & 23.7 & 64.7 & 30.6 \\
\hline 13 & 60 & 0 & 40 & 42.2 & 51.1 & 46.5 & 22.6 & 63.7 & 30.3 \\
\hline 14 & 60 & 40 & 0 & 43 & 48.8 & 41.4 & 23.2 & 60.2 & 24.8 \\
\hline 15 & 80 & 0 & 20 & 42.1 & 49.3 & 38.9 & 22.1 & 60.9 & 22.8 \\
\hline 16 & 100 & 0 & 0 & 40.9 & 49.5 & 37.7 & 20.7 & 61.1 & 21.5 \\
\hline
\end{tabular}

In addition, a number of trends may also be observed:

- For combination of fiber orientation composition of $\left[ \pm 45^{\circ} / 90^{\circ}\right]_{s}$ only (i.e. $0 \%$ content of $0^{\circ}$ fiber orientation), natural frequency appears to increase when the composition of $\pm 45^{\circ}$ orientation increases, for all boundary conditions except for FSFS boundary condition (where the natural frequency decreases).

- For combination of fiber orientation composition of $\left[0^{\circ} / 90^{\circ}\right]_{s}$ only (i.e. $0 \%$ content of $\pm 45^{\circ}$ fiber orientation), natural frequency appears to decrease if the composition of $90^{\circ}$ fiber orientation decreases.

- For combination of $\left[0^{\circ}{ }_{n} / \pm 45^{\circ}{ }_{n}\right]_{s}$ orientation composition only (i.e. $0 \%$ content of $90^{\circ}$ fiber orientation), natural frequency tend to decrease if the composition of $\pm 45^{\circ}$ fiber orientation decreases.

- Natural frequency tend to increase when the angle orientation increases for the combination where all fiber orientation $\left[0^{\circ}{ }_{n} / \pm 45^{\circ}{ }_{n} / 90^{\circ}{ }_{n}\right]_{s}$ are present.

Examining cases 16, 15 and 1, when fiber orientation changes from $0^{\circ}$ to $\pm 45^{\circ}$, natural frequency appears to increase. 
However, when the fiber orientation changes from $\pm 45^{\circ}$ to $90^{\circ}$ the natural frequency appears decrease. Furthermore, there appears no change in natural frequency when the fiber orientation changes from $0^{\circ}$ to $90^{\circ}$ for SSSS and CCCC plates, but at FSFS and SSFS plates the natural frequency tends to increase. However, the natural frequency appears to decrease when the fiber orientation changes from $0^{\circ}$ to $90^{\circ}$ for plates with boundary conditions CSSS and CFCF. This shows that natural frequencies are affected by the imposed boundary conditions on the laminated plates.

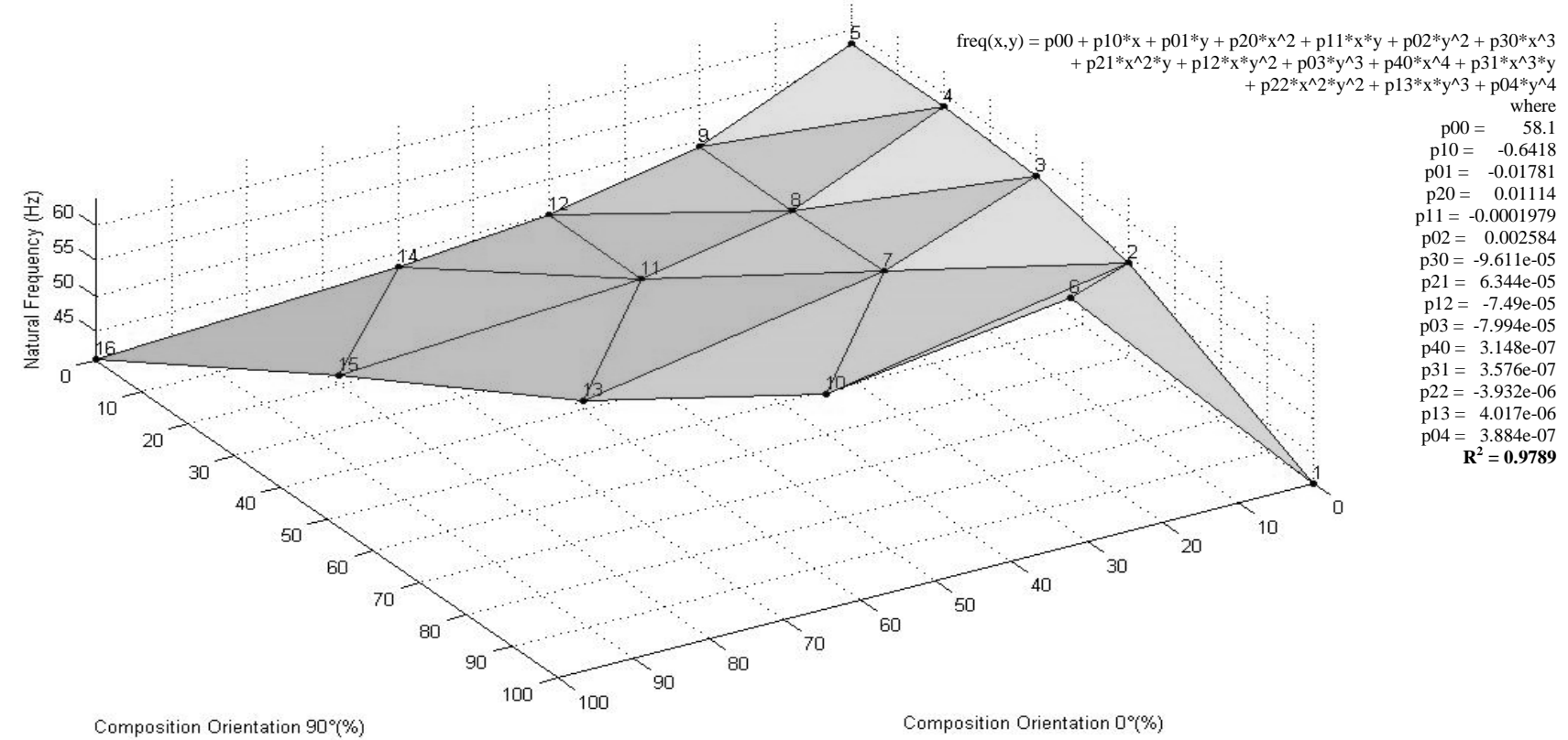

Fig. 6. Simple-simple-simple-simple (SSSS) boundary condition

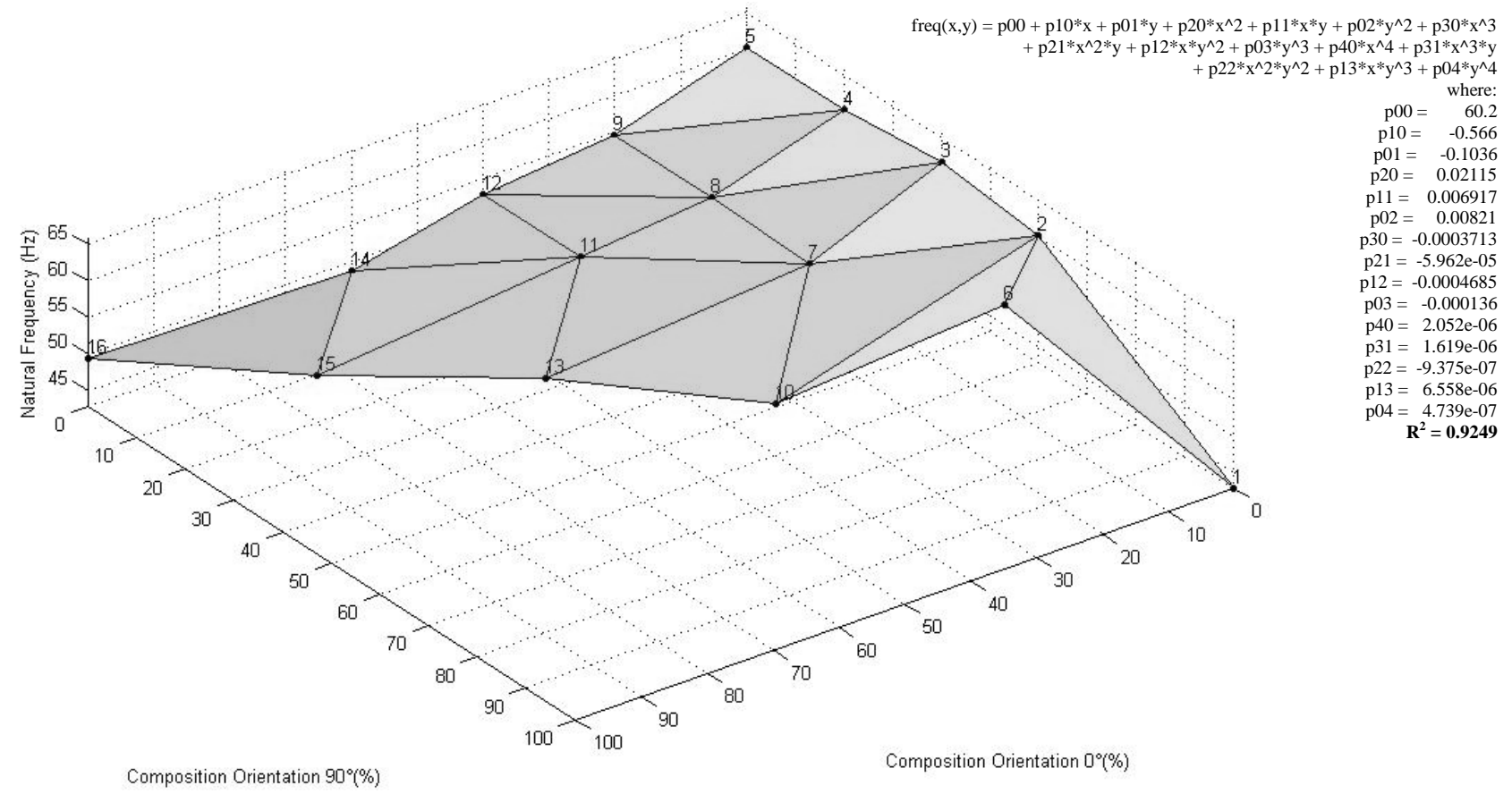

Fig. 7. Clamped-simple-simple-simple (CSSS) boundary condition 


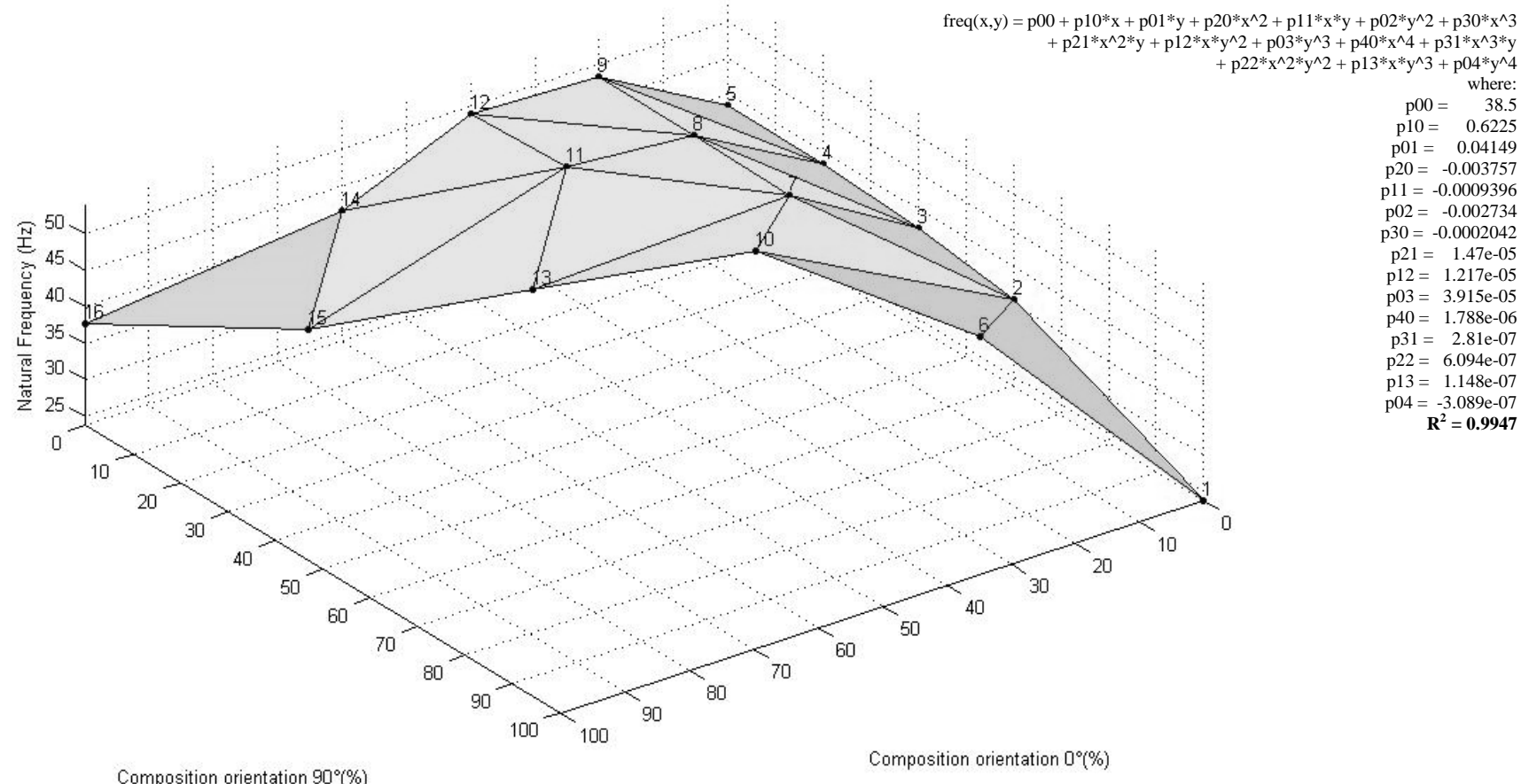

Fig. 8. Clamped-free-clamped-free (CFCF) boundary condition

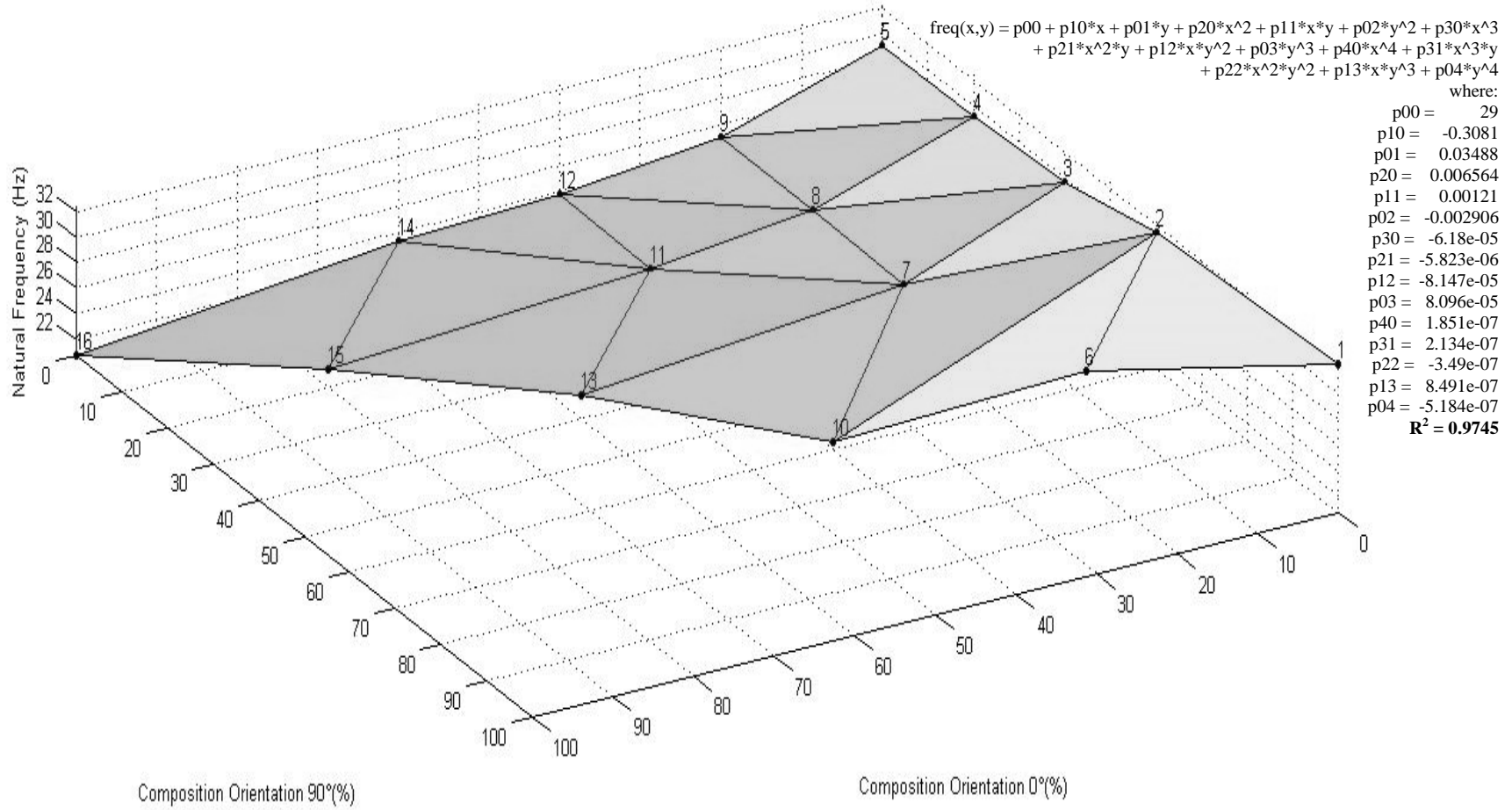

Fig. 9. Free-simple-free-simple (FSFS) boundary condition 


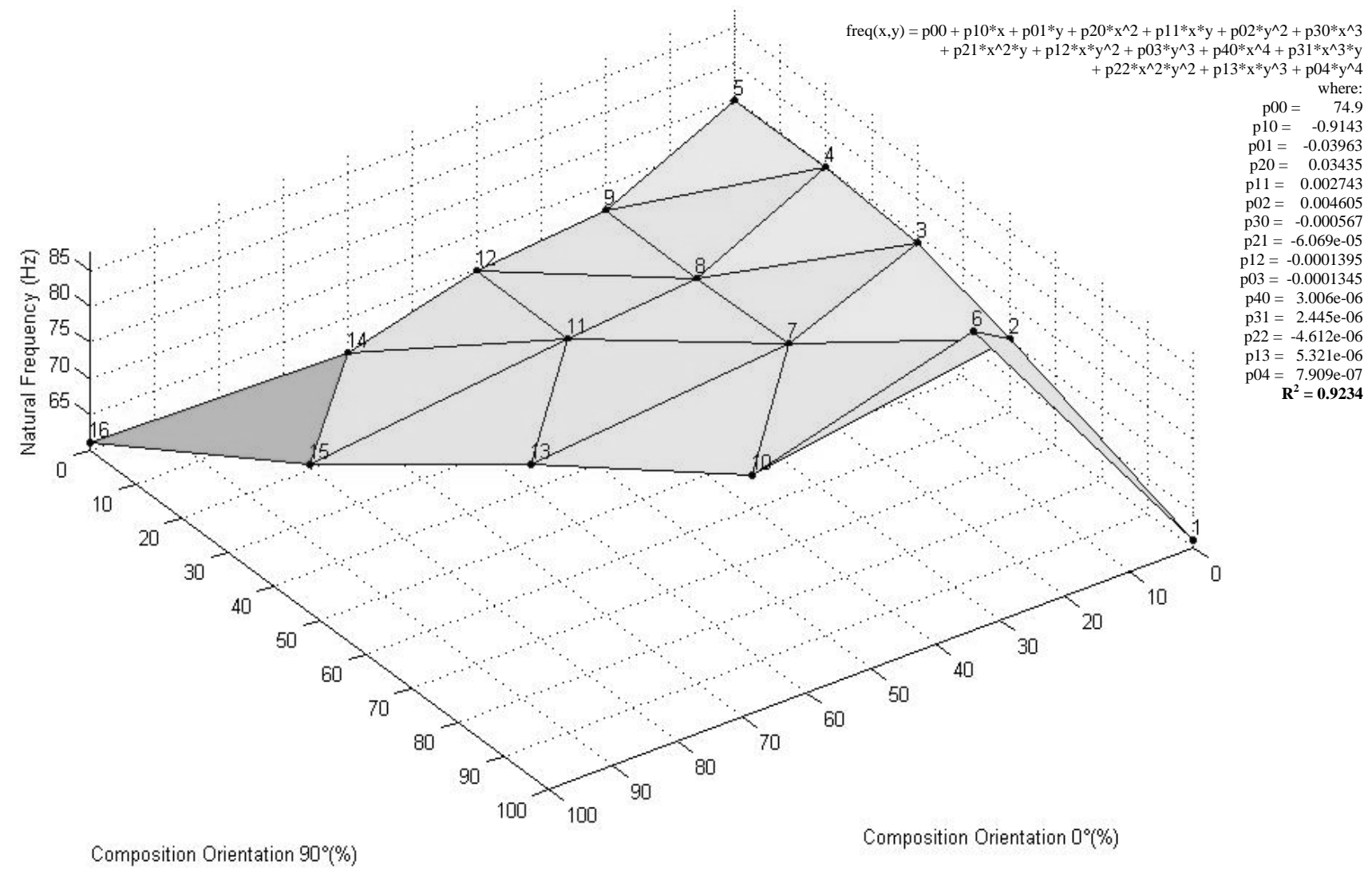

Fig. 10. Clamped-clamped-clamped-clamped (CCCC) boundary condition

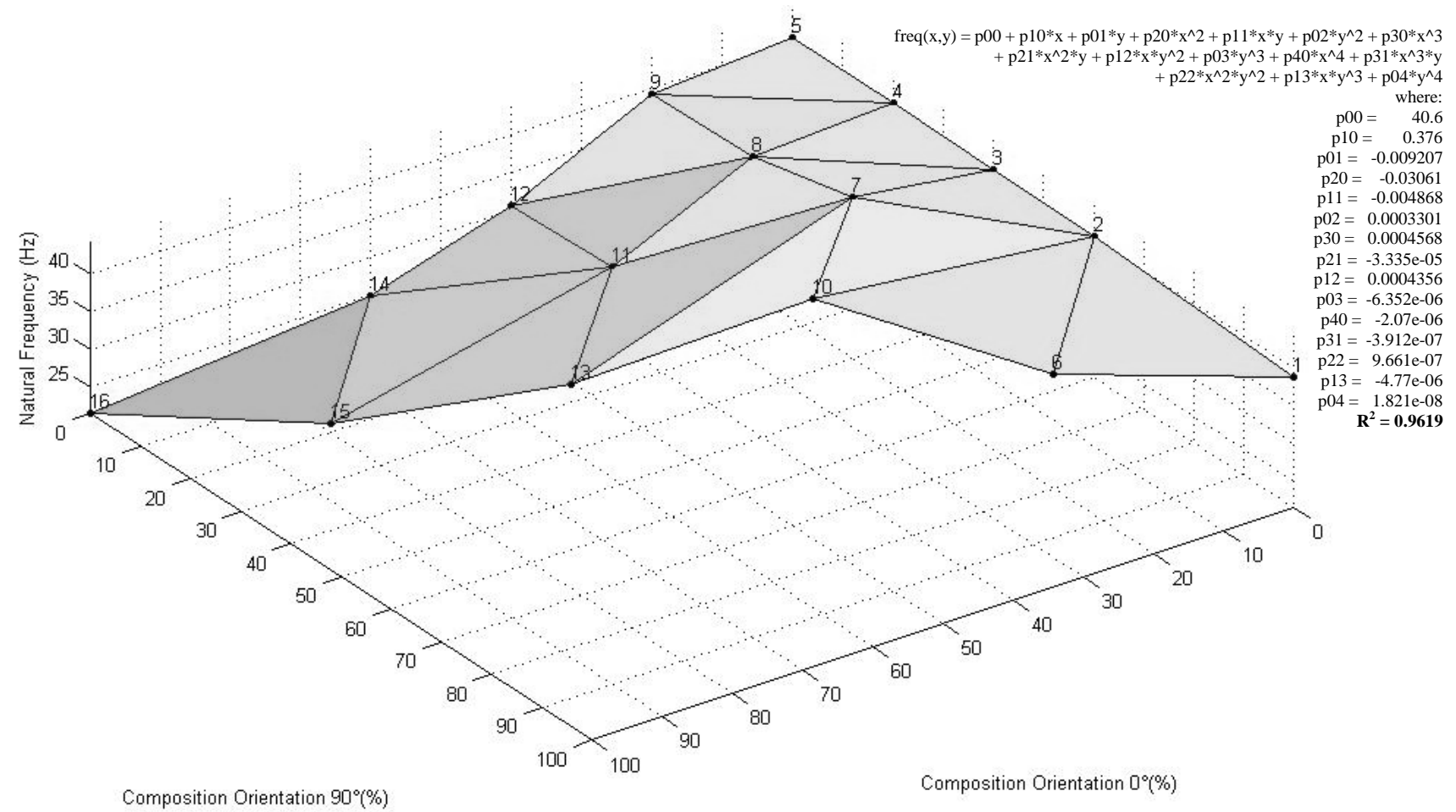

Fig. 11. Simple-simple-free-simple (SSFS) boundary condition

\section{B. Effect of change in fiber orientation composition on mode shape}

Fig. $12-17$ shows the effect of $\%$ in $0^{\circ}, \pm 45^{\circ}$ and $90^{\circ}$ fiber orientation composition on laminated plate mode shape. The first 5 mode shapes were obtained from the FEM simulation, but mode shape 5 is reported here. Based on the numerical results, the following may be observed:

- For combination of $\left[ \pm 45^{\circ} / 90^{\circ}\right]_{s}$ orientation composition only (i.e. $0 \%$ of $0^{\circ}$ fiber orientation),

\section{Published By:}

\& Sciences Publication

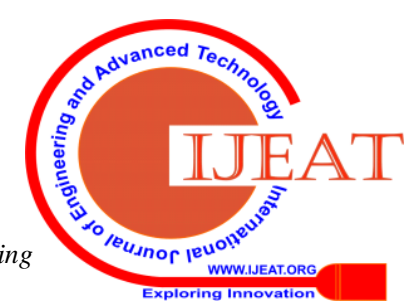




\section{Vibration Characteristics of Carbon Fiber Reinforced Polymer Composites under Varying Fiber Orientation Composition}

- when the \% composition of $\pm 45^{\circ}$ orientation is increased, the mode shape change appears for SSSS, CSSS, CFCF and CCCC plate boundary conditions. Instead, the mode shape does not change when composition of $\pm 45^{\circ}$ orientation increase for FSFS and SSFS plate.

- For combination of $\left[0^{\circ} / 90^{\circ}{ }_{n}\right]_{s}$ orientation composition only (i.e. $0 \%$ of $\pm 45^{\circ}$ fiber orientation), change in mode shape appears when the composition of $90^{\circ}$ orientation decreases, for all SSSS, CSSS, CFCF, FSFS, CCCC and SSFS plate boundary conditions.

- For combination of $\left[0^{\circ}{ }_{n} / \pm 45^{\circ}\right]_{s}$ orientation composition only (i.e. $0 \%$ of $90^{\circ}$ fiber orientation), mode shape changes when the composition of $\pm 45^{\circ}$ orientation decreases. Combination of $\left[0^{\circ}{ }_{n} / \pm 45^{\circ}\right]_{s}$ orientation composition and combination of $\left[ \pm 45^{\circ} / 90^{\circ}\right]_{s}$ orientation composition for SSSS and CCCC plate is

\section{Combination of composition} orientation of $\left[ \pm 45^{\circ}{ }_{n} / 90^{\circ}{ }_{n}\right]_{s}$

Combination of composition orientation $\left[0^{\circ}{ }_{n} / 90^{\circ}\right]_{s}$

Combination of composition orientation $\left[0^{\circ} / \pm 45^{\circ}\right]_{s}$,

Combination of composition orientation $\left[0^{\circ}{ }_{n} / \pm 45^{\circ}{ }_{n} / 90^{\circ}\right]_{s}$

Changing of angle orientation from $0^{\circ}$ to $\pm 45^{\circ}$ to $90^{\circ}$.
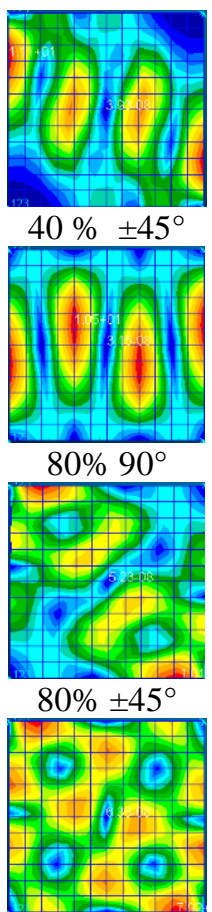

$\left[0 \% 0^{\circ} /-45^{\circ} /\right.$ $\left.45^{\circ} / 90^{\circ}\right] \mathrm{s}$

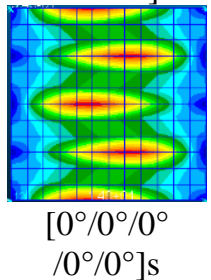

equivalent, but their mode shape at these combination are not similar, showing that change of mode shapes are affected by stacking sequence of the layer in the laminated plate.

- For combination of $\left[0^{\circ}{ }_{n} / \pm 45^{\circ}{ }_{n} / 90^{\circ}{ }_{n}\right]_{s}$ fiber orientation compositions, mode shape changes when the angle of orientation at every layer increases for SSSS, CSSS, CFCF, FSFS and CCCC plate boundary conditions. Instead, the mode shape does not change when the angle of orientation increase for SSFS plate boundary conditions.

- Mode shape change when fiber orientation changes from $0^{\circ}$ to $\pm 45^{\circ}$ to $90^{\circ}$ for the SSSS, CSSS, CFCF, FSFS, CCCC and SSFS plate boundary conditions.

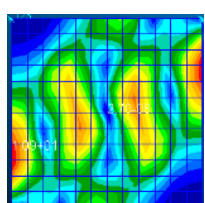

$60 \% \pm 45^{\circ}$

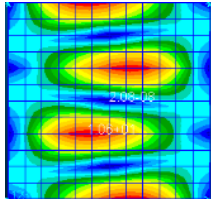

$60 \% 90^{\circ}$

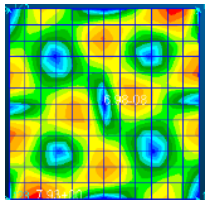

$60 \% \pm 45^{\circ}$

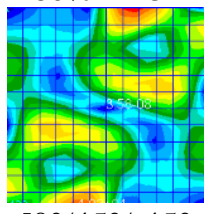

$\left[0^{\circ} / 45^{\circ} /-45^{\circ}\right.$

$\left.145^{\circ} / 90^{\circ}\right] \mathrm{s}$

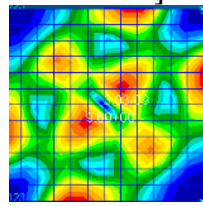

$\left[45^{\circ} /-45^{\circ} / 45^{\circ}\right.$

$\left./-45^{\circ} / 45^{\circ}\right] \mathrm{s}$

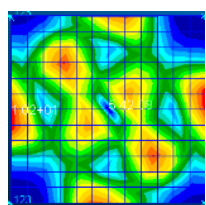

$80 \% \pm 45^{\circ}$

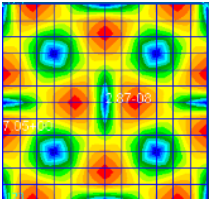

$40 \% 90^{\circ}$
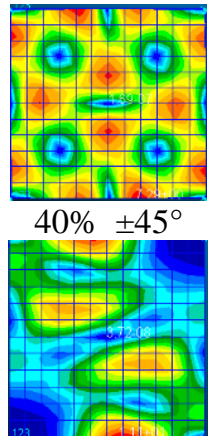

$\left[0 \%-45^{\circ} / 45^{\circ}\right.$

$\left.190^{\circ} / 90^{\circ}\right] \mathrm{s}$

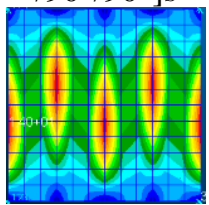

$\left[90^{\circ} / 90^{\circ} / 90^{\circ}\right.$

$\left.190^{\circ} / 90^{\circ}\right] \mathrm{s}$

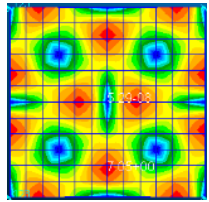

$20 \% 90^{\circ}$

Fig. 12. SSSS Plate 
Combination of composition orientation of $\left[ \pm 45^{\circ} / 90^{\circ}\right]_{s}$

combination of composition orientation $\left[0^{\circ}{ }_{n} / 90^{\circ}{ }_{n}\right]_{s}$

Combination of composition orientation $\left[0^{\circ} \mathrm{n} / \pm 45^{\circ}\right]_{s}$,

combination of composition orientation $\left[0^{\circ}{ }_{n} / \pm 45^{\circ} / 90^{\circ}\right]_{s}$

Changing of angle orientation from $0^{\circ}$ to $\pm 45^{\circ}$ to $90^{\circ}$.

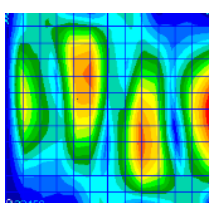

$40 \% \pm 45^{\circ}$

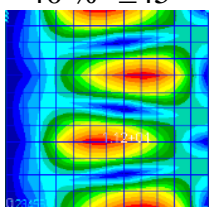

$80 \% 90^{\circ}$

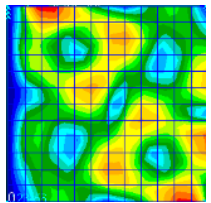

$80 \% \pm 45^{\circ}$

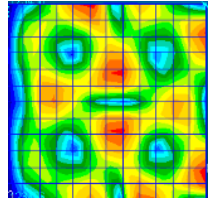

$\left[0 \% 0^{\circ} /-45^{\circ}\right.$

$\left.145^{\circ} / 90^{\circ}\right] \mathrm{s}$

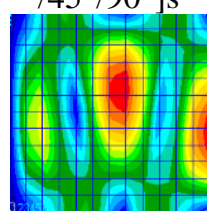

$\left[0^{\circ} / 0^{\circ} / 0^{\circ}\right.$

$\left.10^{\circ} / 0^{\circ}\right] \mathrm{s}$

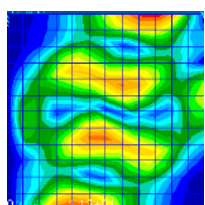

$60 \% \pm 45^{\circ}$

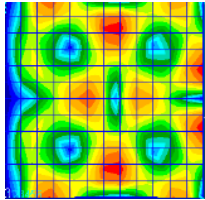

$60 \% 90^{\circ}$

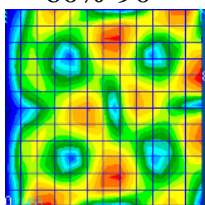

$60 \% \pm 45^{\circ}$

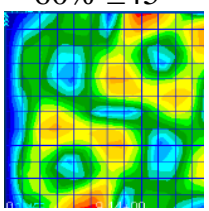

$\left[0^{\circ} / 45^{\circ} /-45^{\circ}\right.$

$\left./ 45^{\circ} / 90^{\circ}\right] \mathrm{s}$

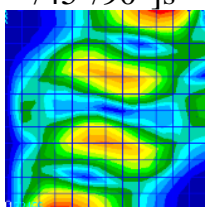

$\left[45^{\circ} /-45^{\circ} / 45^{\circ}\right.$ $\left./-45^{\circ} / 45^{\circ}\right] \mathrm{s}$

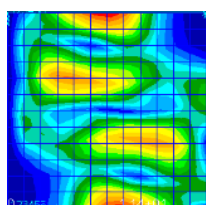

$80 \% \pm 45^{\circ}$

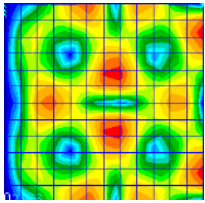

$40 \% 90^{\circ}$

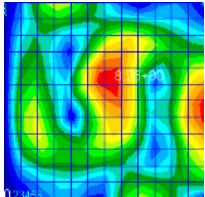

$40 \% \pm 45^{\circ}$

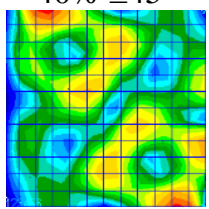

$\left[0^{\circ} /-45^{\circ} / 45^{\circ}\right.$

$\left./ 90^{\circ} / 90^{\circ}\right] \mathrm{s}$

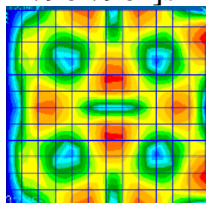

$\left[90^{\circ} / 90^{\circ} / 90^{\circ}\right.$

$\left.190^{\circ} / 90^{\circ}\right] \mathrm{s}$

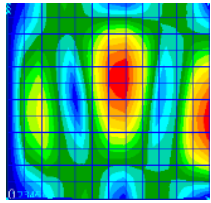

$20 \% 90^{\circ}$

Fig. 13. CSSS Plate

Combination of composition orientation of $\left[ \pm 45^{\circ}{ }_{n} / 90^{\circ}{ }_{n}\right]_{s}$

Combination of composition orientation $\left[0^{\circ}{ }_{n} / 90^{\circ}{ }_{n}\right]_{s}$

Combination of composition orientation $\left[0^{\circ}{ }_{n} / \pm 45^{\circ}\right]_{s}$,

Combination of composition orientation $\left[0^{\circ}{ }_{n} / \pm 45^{\circ}{ }_{n} / 90^{\circ}\right]_{s}$

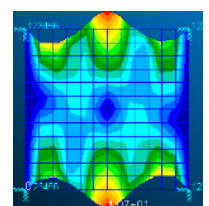

$40 \% \pm 45^{\circ}$

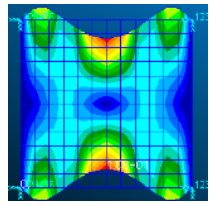

$80 \% 90^{\circ}$

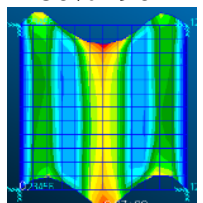

$80 \% \pm 45^{\circ}$

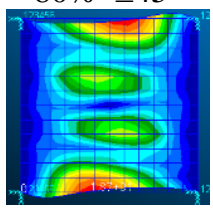

$\left[0^{\circ} / 0^{\circ} /-45^{\circ}\right.$

$\left.145^{\circ} / 90^{\circ}\right] \mathrm{s}$
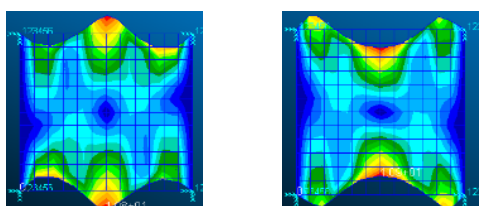

$80 \% \pm 45^{\circ}$

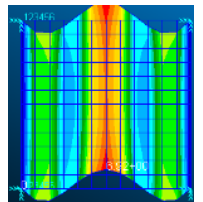

$60 \% 90^{\circ}$

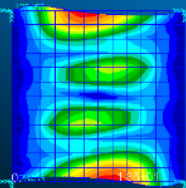

$60 \% \pm 45^{\circ}$

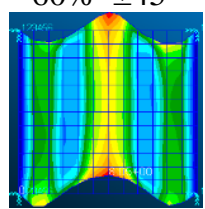

$\left[0^{\circ} / 45^{\circ} /-45^{\circ}\right.$ $\left.145^{\circ} / 90^{\circ}\right] \mathrm{s}$

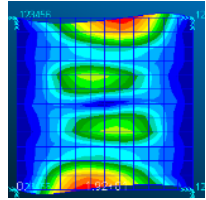

$40 \% 90^{\circ}$

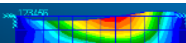

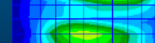

$+$

$+4$

10

$40 \% \pm 45^{\circ}$

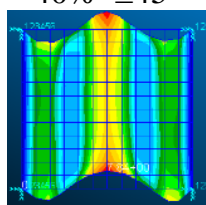

$\left[0 \%-45^{\circ} / 45^{\circ}\right.$

$\left.190^{\circ} / 90^{\circ}\right] \mathrm{s}$

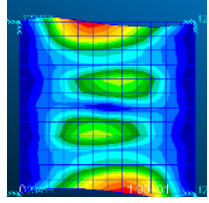

$20 \% 90^{\circ}$

Fig. 14. (cont.)

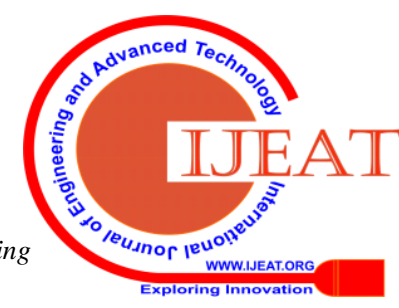


Vibration Characteristics of Carbon Fiber Reinforced Polymer Composites under Varying Fiber Orientation Composition

Changing of angle orientation from $0^{\circ}$ to $\pm 45^{\circ}$ to $90^{\circ}$.

Combination of composition orientation

of $\left[ \pm 45^{\circ} / 90^{\circ}\right]_{\mathrm{s}}$

Combination of composition orientation $\left[0^{\circ} / 90^{\circ}\right]_{\mathrm{s}}$

Combination of composition orientation $\left[0^{\circ} / \pm 45^{\circ}\right]_{s}$,

Combination of composition orientation $\left[0^{\circ}{ }_{\mathrm{n}} / \pm 45^{\circ}{ }_{\mathrm{n}} / 90^{\circ}{ }_{\mathrm{n}}\right]_{\mathrm{s}}$

Changing of angle orientation from $0^{\circ}$ to $\pm 45^{\circ}$ to $90^{\circ}$.

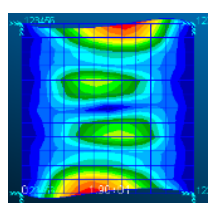

$\left[0^{\circ} / 0^{\circ} / 0^{\circ}\right.$ $\left.10^{\circ} / 0^{\circ}\right] \mathrm{s}$

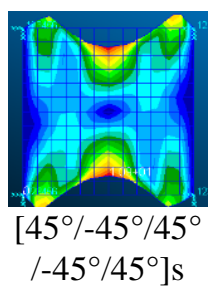

Fig. 14. CFCF Plate

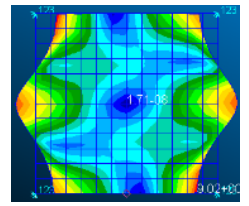

$40 \% \pm 45^{\circ}$

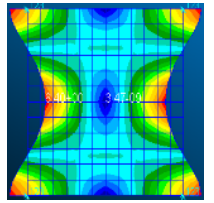

$80 \% 90^{\circ}$

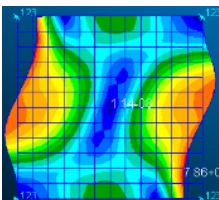

$80 \% \pm 45^{\circ}$

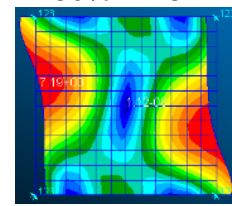

$\left[0^{\circ} / 0^{\circ} /-45^{\circ}\right.$

$\left./ 45^{\circ} / 90^{\circ}\right] \mathrm{s}$

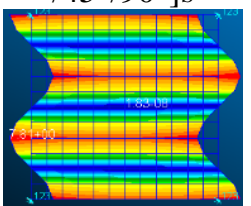

$\left[0^{\circ} / 0^{\circ} / 0^{\circ}\right.$

$\left.10^{\circ} / 0^{\circ}\right] \mathrm{s}$

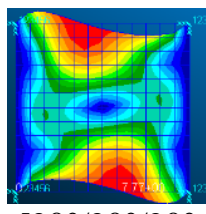

$\left[90^{\circ} / 90^{\circ} / 90^{\circ}\right.$ $\left.190^{\circ} / 90^{\circ}\right] \mathrm{s}$
Combination of composition orientation of $\left[ \pm 45^{\circ}{ }_{n} / 90^{\circ}{ }_{n}\right]_{s}$

Combination of composition orientation $\left[0^{\circ}{ }_{n} / 90^{\circ}{ }_{n}\right]_{\mathrm{s}}$

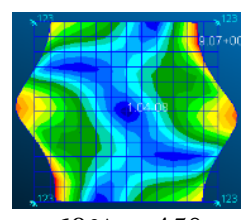

$60 \% \pm 45^{\circ}$

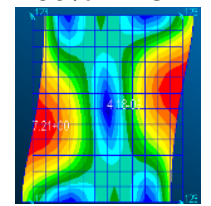

$60 \% 90^{\circ}$

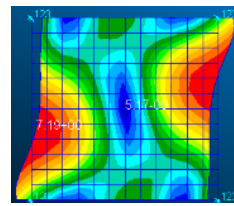

$60 \% \pm 45^{\circ}$

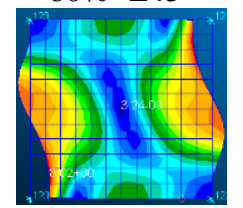

$\left[0^{\circ} / 45^{\circ} / 45^{\circ}\right.$

$\left.145^{\circ} / 90^{\circ}\right] \mathrm{s}$

$\left[45^{\circ} / 45^{\circ} / 45^{\circ}\right.$ / $\left.-45^{\circ} / 45^{\circ}\right] \mathrm{s}$

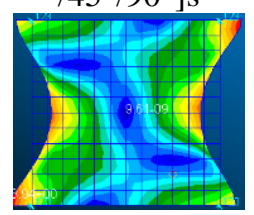

Fig. 15. FSFS Plate

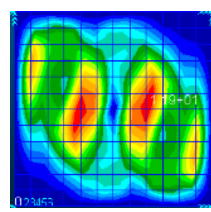

$40 \% \pm 45^{\circ}$

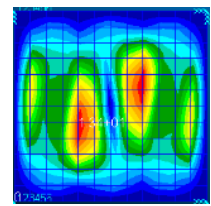

$80 \% 90^{\circ}$

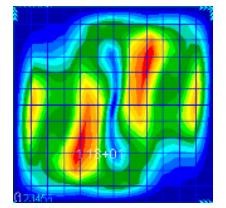

$60 \% \pm 45^{\circ}$

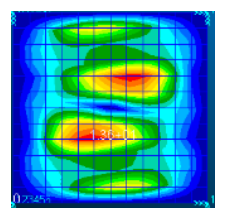

$60 \% 90^{\circ}$
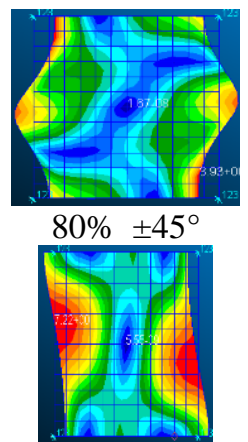

$40 \% 90^{\circ}$

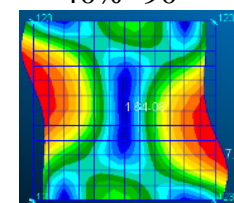

$40 \% \pm 45^{\circ}$

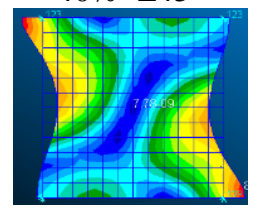

$\left[0^{\circ} /-45^{\circ} / 45^{\circ}\right.$

$\left./ 90^{\circ} / 90^{\circ}\right] \mathrm{s}$

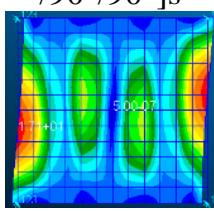

$\left[90^{\circ} / 90^{\circ} / 90^{\circ}\right.$

$/ 90^{\circ} / 90^{\circ} \mathrm{]s}$

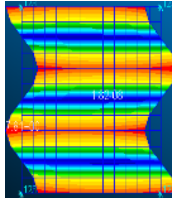

$20 \% 90^{\circ}$

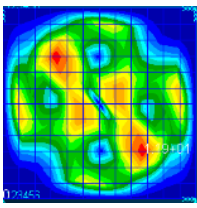

$80 \% \pm 45^{\circ}$

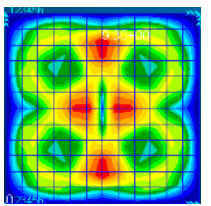

$40 \% 90^{\circ}$

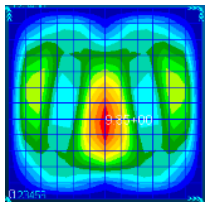

$20 \% 90^{\circ}$

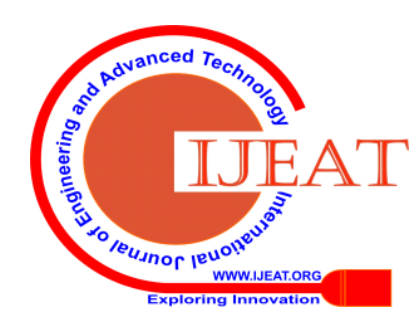


Combination of

composition orientation

$\left[0^{\circ}{ }_{n} / \pm 45^{\circ}\right]_{s}$,

Combination of

composition orientation

$\left[0^{\circ} / \pm 45^{\circ}{ }_{n} / 90^{\circ}\right]_{s}$

Changing of angle

orientation from

$0^{\circ}$ to $\pm 45^{\circ}$ to $90^{\circ}$.

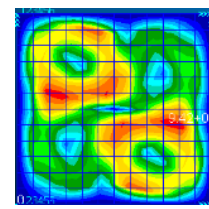

$80 \% \pm 45^{\circ}$

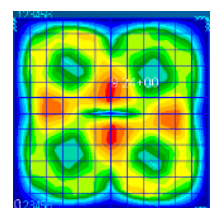

$\left[0 \% 0^{\circ} /-45^{\circ}\right.$

$\left.145^{\circ} / 90^{\circ}\right] \mathrm{s}$

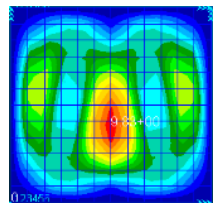

$\left[0^{\circ} / 0^{\circ} / 0^{\circ}\right.$

$\left.10^{\circ} / 0^{\circ}\right] \mathrm{s}$

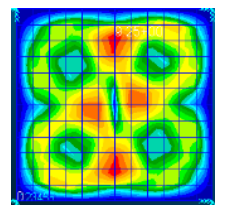

$60 \% \pm 45^{\circ}$

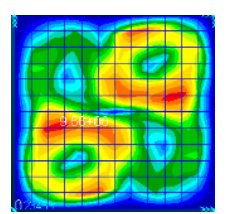

$\left[0^{\circ} / 45^{\circ} /-45^{\circ}\right.$

$\left.145^{\circ} / 90^{\circ}\right] \mathrm{s}$

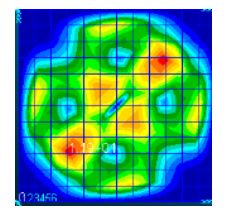

$\left[45^{\circ} /-45^{\circ} / 45^{\circ}\right.$

$\left./-45^{\circ} / 45^{\circ}\right] \mathrm{s}$

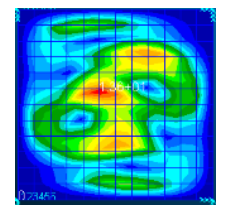

$40 \% \pm 45^{\circ}$

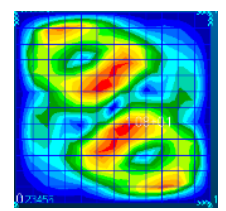

$\left[0^{\circ} /-45^{\circ} / 45^{\circ}\right.$

$\left.190^{\circ} / 90^{\circ}\right] \mathrm{s}$

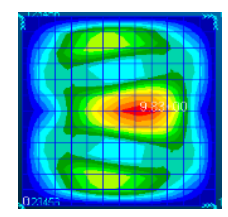

$\left[90^{\circ} / 90^{\circ} / 90^{\circ}\right.$

$190^{\circ} / 90^{\circ} \mathrm{s}$

Fig. 16. CCCC Plate

Combination of composition orientation of $\left[ \pm 45^{\circ}{ }_{n} / 90^{\circ}{ }_{n}\right]_{s}$

Combination of composition orientation $\left[0^{\circ}{ }_{n} / 90^{\circ}{ }_{n}\right]_{s}$

Combination of composition orientation $\left[0^{\circ}{ }_{n} / \pm 45^{\circ}\right]_{s}$,

Combination of composition orientation $\left[0^{\circ}{ }_{n} / \pm 45^{\circ} / 90^{\circ}\right]_{s}$

Changing of angle orientation from $0^{\circ}$ to $\pm 45^{\circ}$ to $90^{\circ}$.

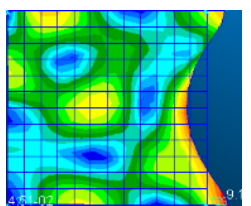

$40 \% \pm 45^{\circ}$

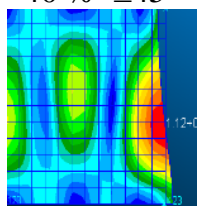

$80 \% 90^{\circ}$

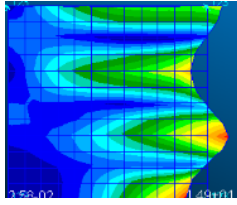

$80 \%+45^{\circ}$
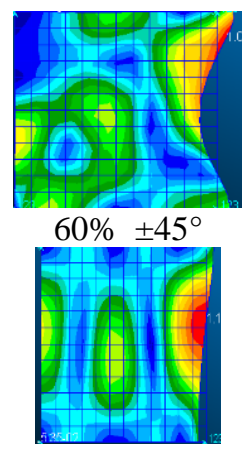

$60 \% 90^{\circ}$

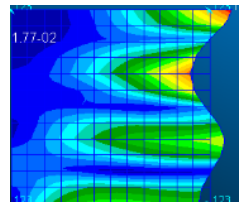

$60 \% \pm 45^{\circ}$

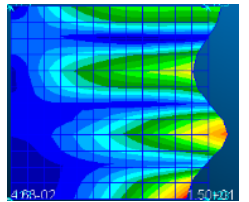

$\left[0^{\circ} / 0^{\circ} /-45^{\circ}\right.$

$145^{\circ} / 90^{\circ} \mathrm{s}$

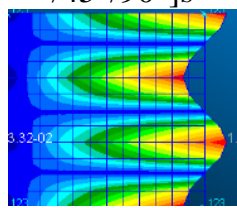

$\left[0^{\circ} / 0^{\circ} / 0^{\circ}\right.$

$\left.10^{\circ} / 0^{\circ}\right] \mathrm{s}$

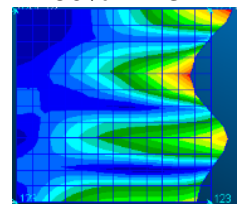

$\left[0^{\circ} / 45^{\circ} /-45^{\circ}\right.$

$\left./ 45^{\circ} / 90^{\circ}\right] \mathrm{s}$

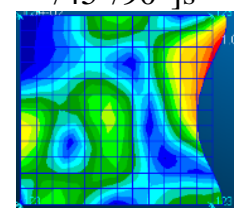

$\left[45^{\circ} /-45^{\circ} / 45^{\circ}\right.$ $\left./-45^{\circ} / 45^{\circ}\right] \mathrm{s}$

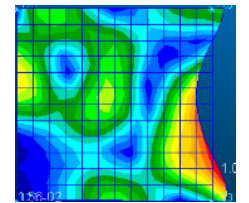

$80 \% \pm 45^{\circ}$

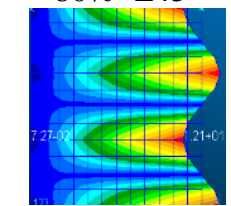

$40 \% 90^{\circ}$

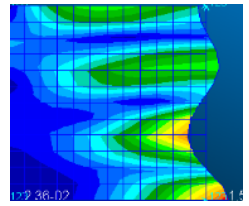

$40 \% \pm 45^{\circ}$

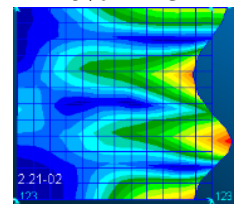

$\left[0^{\circ} /-45^{\circ} / 45^{\circ}\right.$ $\left.190^{\circ} / 90^{\circ}\right] \mathrm{s}$

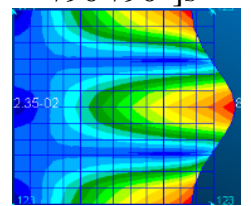

$\left[90^{\circ} / 90^{\circ} / 90^{\circ}\right.$ $190^{\circ} / 90^{\circ} \mathrm{]s}$

Fig. 17. SSFS Plate

\section{Effect stacking sequence on natural frequency}

The effect of stacking sequence on natural frequency, as shown in Fig. 18-23, is analyzed. For this study, composite laminated plate with fixed \% of fiber orientation composition

is applied - i.e. $20 \%$ composition of $0^{\circ}$ fiber orientation,

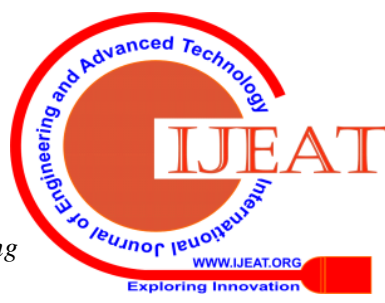




\section{Vibration Characteristics of Carbon Fiber Reinforced Polymer Composites under Varying Fiber Orientation Composition}

$60 \%$ composition of $\pm 45^{\circ}$ fiber orientation and $20 \%$ composition of $90^{\circ}$ fiber orientation. We focused on 6 layups - case 1, 2, 3, 4, 5 and 6, which respectively are $\left[45^{\circ} /-45^{\circ} / 45^{\circ} / 0^{\circ} / 90^{\circ}\right]_{\mathrm{s}}$, $\left[45^{\circ} /-45^{\circ} / 45^{\circ} / 90^{\circ} / 0^{\circ}\right]_{s}$ $\left[0^{\circ} / 45^{\circ} /-45^{\circ} / 45^{\circ} / 90^{\circ}\right]_{\mathrm{s}}$ $\left[90 \% / 45^{\circ} /-45^{\circ} / 45^{\circ} / 0^{\circ}\right]_{\mathrm{s}}$ $\left[0 \% / 90^{\circ} / 45^{\circ} /-45^{\circ} / 45^{\circ}\right]_{\mathrm{s}}$ and $\left[90^{\circ} / 0^{\circ} / 45^{\circ} /-45^{\circ} / 45^{\circ}\right]_{\text {s. }}$. Cases 6,3 and 2 were considered the non-reversed order, while cases 1 , 4 and 5 represented the reversed order respectively.

The natural frequency does not change if stacking sequence was changed from $\left[0^{\circ} / 45^{\circ} /-45^{\circ} / 45^{\circ} / 90^{\circ}\right]_{\mathrm{s}}$ to $\left[90^{\circ} / 45^{\circ} /-45^{\circ} / 45^{\circ} / 0^{\circ}\right]_{\mathrm{s}}$ for SSSS and CCCC plate boundary conditions. However, the natural frequency decreased when the stacking sequence changed from $\left[0^{\circ} / 45^{\circ} /-45^{\circ} / 45^{\circ} / 90^{\circ}\right]_{s}$ to $\left[90^{\circ} / 45^{\circ} /-45^{\circ} / 45^{\circ} / 0^{\circ}\right]_{s}$ for CSSS and CFCF plate boundary conditions. Instead, natural frequency increased when the stacking sequence was changed from $\left[0^{\circ} / 45^{\circ} /-45^{\circ} / 45^{\circ} / 90^{\circ}\right]_{\mathrm{s}}$ to $\left[90^{\circ} / 45^{\circ} /-45^{\circ} / 45^{\circ} / 0^{\circ}\right]_{\mathrm{s}}$ for plate with FSFS and SSFS boundary conditions.

When stacking sequence was changed from $\left[45^{\circ} /-45^{\circ} / 45^{\circ} / 90^{\circ} / 0^{\circ}\right]_{\mathrm{s}}$ to $\left[0 \% / 90^{\circ} / 45^{\circ} /-45^{\circ} / 45^{\circ}\right]_{\mathrm{s}}$, the natural frequency increased for plate with SSSS, CFCF and CCCC boundary conditions. Instead, the natural frequency decreased when stacking sequence changed from $\left[45^{\circ} /-45^{\circ} / 45^{\circ} / 90^{\circ} / 0^{\circ}\right]_{\mathrm{s}}$ to $\left[0^{\circ} / 90^{\circ} / 45^{\circ} /-45^{\circ} / 45^{\circ}\right]_{\mathrm{S}}$ for CSSS, FSFS and SSFS plate boundary conditions.

For stacking sequence change from $\left[90^{\circ} / 0^{\circ} / 45^{\circ} /-45^{\circ} / 45^{\circ}\right]_{\mathrm{s}}$ to $\left[45^{\circ} /-45^{\circ} / 45^{\circ} / 0^{\circ} / 90^{\circ}\right]_{\text {s }}$, plates with SSSS, CSSS, FSFS and CCCC boundary conditions showed decrement in their natural frequency, but increment in natural frequency for CFCF and SSFS plate boundary conditions.

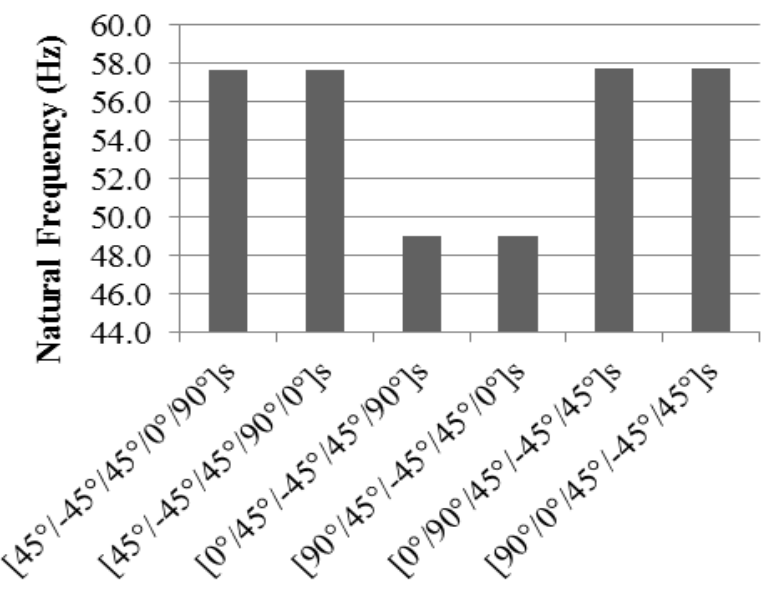

Fig. 18. SSSS Plate

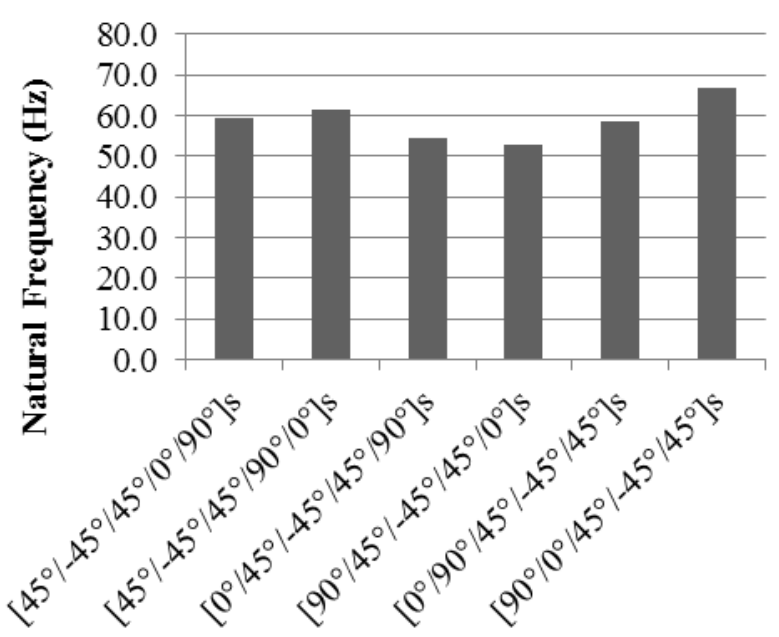

Fig. 19. CSSS Plate

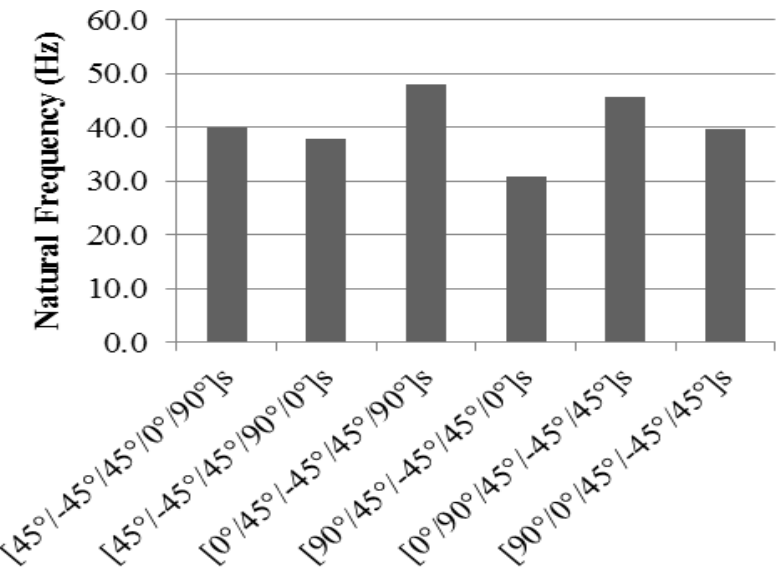

Fig. 20. CFCF Plate

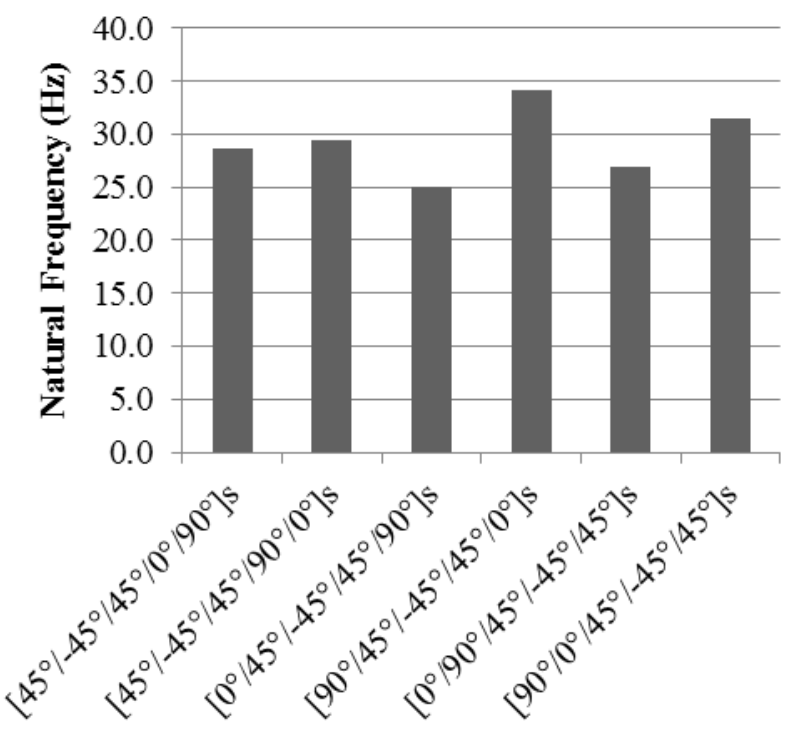

Fig. 21. FSFS Plate 


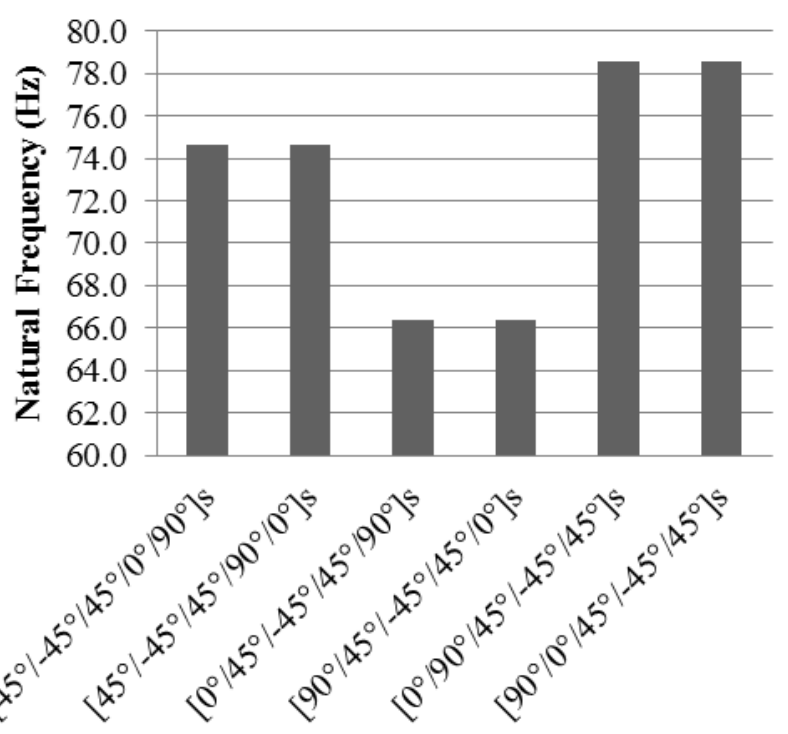

Fig. 22. CCCC Plate

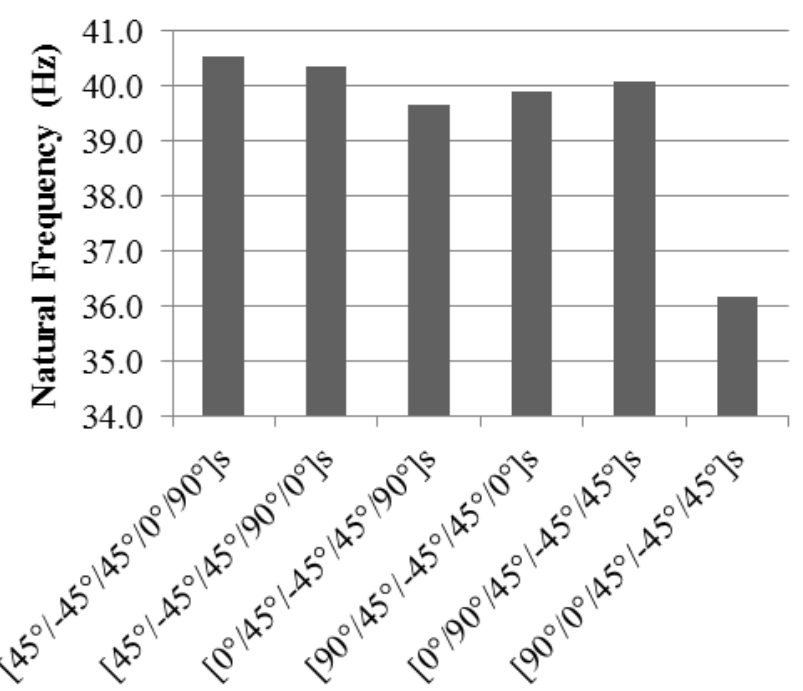

Fig. 23. SSFS Plate

\section{CONCLUSION}

In this paper, 16 cases or layups of $\left[0^{\circ}{ }_{n} / \pm 45^{\circ}{ }_{n} / 90^{\circ}\right]_{s}$ fiber orientation composition were studied to show the effect of fiber orientation composition on natural frequency and mode shape of laminated composite plates. The modal analysis were undertaken using finite element method for 6 configurations of plate boundary conditions. Both mesh-independence study and benchmarking with previous work, were undertaken to validate the present model. Computational results show that natural frequency and mode shape are affected by $\%$ composition of $\left[0^{\circ} / \pm 45^{\circ} / 90^{\circ}\right]$ fiber orientations, boundary conditions and stacking sequence of the laminate. Natural frequency to \% fiber orientation composition relationships for $\left[0^{\circ} \mathrm{n} / \pm 45^{\circ}{ }_{\mathrm{n}} / 90^{\circ}{ }_{\mathrm{n}}\right]_{\mathrm{s}}$ laminated composite plates may be found, which could be exploited to customize required laminate content to suit design requirements.The present study had focused on carbon fiber reinforced polymer (CFRP) laminates, which could be extended to glass fibers or other types of fibers used in engineering applications, for future investigations. In addition, due to practical engineering reasons, the present study had limited our attention to $\left[0^{\circ}{ }_{\mathrm{n}} / \pm 45^{\circ} \mathrm{n} / 90^{\circ}{ }_{\mathrm{n}}\right]_{\mathrm{s}}$ layups, which may also be extended to other combination of fiber orientations for future work.

\section{ACKNOWLEDGMENT}

The authors would like to gratefully acknowledge the support provided by computing facilities in the Department of Mechanical Engineering, Faculty of Engineering and Built Environment, Universiti Kebangsaan Malaysia.

\section{REFERENCES}

1. T. P. Sathishkumar, S. Satheeshkumar, J. Naveen, "Glass fiber-reinforced polymer composites - A review", Journal of Reinforced Plastics and Composites, Vol. 33, No. 13, 2014, pp. 1258-1275.

2. B. M. Yassin, R. Zulkifli, W. R. W. Daud, S. Abdullah, "Flexural behaviour of uni-directional kenaf composites using experimental and simulation methods", International Journal of Mechanical \& Mechatronics Engineering IJMME-IJENS Vol. 16, No. 4, 2016, pp. 57-64.

3. M. J. Ghoushji, R. A Eshkoor, R. Zulkifli, A. B. Sulong, S. Abdullah, C. H. Azhari, "Energy Absorption Capability of Axially Compressed Woven Natural Ramie/Green Epoxy Square Composite Tubes", Journal of Reinforced Plastics and Composites, Vol. 36, No. 14, 2017, pp. 1028-1037.

4. J. Bachmann, C. Hidalgo, S. Bricout, "Environmental analysis of innovative sustainable composites with potential use in aviation sector- A life cycle assessment review", Science China Technological Sciences, Vol. 60, 2017, pp. 1301-1317.

5. M. R. Rasani,, A. K. Ariffin, M. Bashir, J. Wang, "Effect of Location in a Cylinder Wake on Dynamics of a Flexible Energy Harvesting Plate", Journal of Advanced Research in Fluid Mechanics and Thermal Sciences Vol. 55, No. 2, 2019, 189-198.

6. M. A. F. Ahmad, M. Z. Nuawi, J. A. Ghani, S. Abdullah, A. N. Kasim, "Tool wear monitoring using macro fibre composite as a vibration sensor via I-kaz ${ }^{\mathrm{TM}}$ statistical signal analysis", ARPN Journal of Engineering and Applied Sciences Vol. 13, No. 11, 2018, pp. 3607-3616.

7. R. Zulkifli, T. K. Thye, M. F. M. Tahir, A. R. Ismail, M. J. M. Nor, "Automotive noise insulation composite panel using natural fibres with different perforation areas", Applied Mechanics and Materials, Vol. 165, 2012, pp. 63-67.

8. M. H. Sadr, H. G. Bargh, M. K. Nejadi, H. Pourzand, "Free vibration analysis of rotating laminated composite panels using finite strips method with modified shape function", ASME 2011 International Mechanical Engineering Congress and Exposition (IMECE 2011), Vol. 8, 2011, pp. 747-793.

9. J. K. Ahmed, V. C. Agarwal, P. Pal, V. Srivastav, "Static and dynamic analysis of composite laminate plate", International Journal of Innovative Technology and Exploring Engineering, Vol. 3, No. 6, 2013, pp. 56-60

10. C. V. Srinivasa, Y. J. Suresh, W. P. Kumar, "Experimental and finite element studies on free vibration of skew plates", International Journal of Advanced Structural Engineering, Vol. 6, No. 1, 2014, pp.48.

11. M. Balci, M. O. Nalbant, E. Kara, Ö Gündoğdu, "Free vibration analysis of laminated composite beam with various boundary conditions", International Journal of Automotive and Mechanical Engineering, Vol. 9, 2014, pp. 1734-1746.

12. P. Huifen, W. Cheng, W. Peng, "Effect of fiber orientation on vibration characteristic of composite laminated plates", 4th International Conference on Applied Mechanics, Materials and Manufacturing (ICAMMM 2014), Vol. 670-671, 2014, pp. 158-163.

13. P. Pingulkar, B. Suresha, "Free vibration analysis of laminated composite plate using finite element method", Polymer \& Polymer Composites, Vol. 24, No. 7, 2016, pp. 529-538.

14. I. E. M. Mahdi, O. M. E. Suleiman, "Influence of fiber orientation on the natural frequencies of laminated composite beams", International Journal of Engineering Research and Advanced Technology, Vol. 3, No. 9, 2017, pp. 31-42.

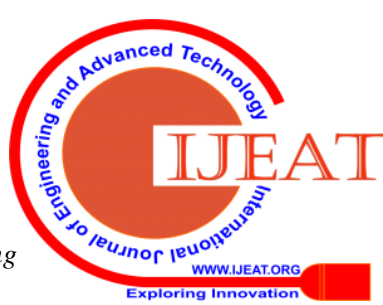




\section{Vibration Characteristics of Carbon Fiber Reinforced Polymer Composites under Varying Fiber Orientation Composition}

15. M. A. M. Norman, M. A. Zainuddin, J. Mahmud, "The effect of various fiber orientation and boundary conditions on natural frequencies of laminated composite beam", International Journal of Engineering and Technology (UAE), Vol. 7, No. 3, 2018, pp. 67-71.

16. S. Khare, N. D. Miital, "Free vibration of thick laminated circular and annular plates using three-dimensional finite element analysis", Alexandaria Engineering Journal, Vol. 57, No. 3, 2018, pp. 1217-1228.

17. F. Kadioglu, T. Coskun, M. Elfarra, "Investigation of dynamic properties of a polymer matrix composite with different angles of fiber orientations", IOP Conference Series: Materials Science and Engineering, Vol. 369, No. 1, 2018, 012037

18. R. A. Muhammet, G. Ömer, K. Barbaros, B. Gürbüz, K. A. Okan, H. Osman, "Effect of orientation angles on vibration properties at carbon fiber reinforced polymeric composites", Engineering Sciences, Vol. 13, No. 3, 2018, pp. 180-189.

19. Y.-S. Lee, K.-D. Lee, "On the dynamic response of laminated circular cylindrical shells under impulse loads", Computers and Structures , Vol. 63, No. 1, 1997, pp. 149-157.

\section{AUTHORS PROFILE}

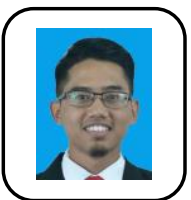

Nazirul Muhaimin Hamzi completed his B. Eng (Hons.) in Mechanical Engineering from Universiti Kebangsaan Malaysia. He is currently pursuing his M.Sc. (by research) in reliability and optimization of suspension arms using lattice structures.

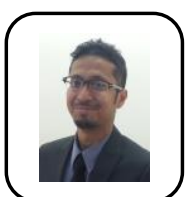

Dr. Mohammad Rasidi Rasani is a senior lecturer at the Center for Integrated Design of Advanced Mechanical Systems (PRISMA), Faculty of Engineering and Built Environment, Universiti Kebangsaan Malaysia. He has more than 5 years working experience in composite structure analysis and his research interests include fluid-structure interactions and finite element methods.

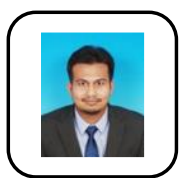

Dr. Mohd Faizal Mat Tahir is a faculty member at the Center for Integrated Design of Advanced Mechanical Systems (PRISMA), Faculty of Engineering and Built Environment, Universiti Kebangsaan Malaysia. He earned both his Bachelor degree and Master degree from Universiti Kebangsaan Malaysia (UKM), in the field of Mechanical Engineering. He obtained his PhD degree at Loughborough University, UK, in 2019 from the school of Aeronautical, Automotive, Chemical and Material Engineering. His research interest are in the field of noise and vibration, ergonomic and digital image correlation.

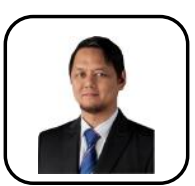

Dr. Mohammad Hamdan Sanusi completed his Bachelor of Aeronautical Engineering and Master of Engineering in Mechanical Engineering from Rensselaer Polytechnic Institute, Troy, New York USA. He completed his $\mathrm{PhD}$ at Universiti Teknikal Malaysia Melaka in Manufacturing Engineering. Presently, he is working as Principal Staff Engineer at CTRM Aero Composites Sdn. Bhd. in Melaka, Malaysia. He has more than 19 years working experience in Advanced Composite Materials and Processes for Aerospace applications. His area of interests includes Advanced Composite Materials, Manufacturing Processes and Technologies. 